\title{
Nanoscale Technologies in Highly Sensitive Diagnosis of Cardiovascular Diseases
}

\author{
Chaohong Shi', Haotian $\mathrm{Xie}^{2}$, Yifan $\mathrm{Ma}^{3 *}$, Zhaogang Yang ${ }^{4 *}$ and Jingjing Zhang ${ }^{3 *}$ \\ ${ }^{1}$ Department of Rehabilitation Medicine, The First People's Hospital of Wenling, Wenzhou Medical University, Wenling, \\ China, ${ }^{2}$ Department of Mathematics, The Ohio State University, Columbus, OH, United States, ${ }^{3}$ Department of Chemical \\ and Biomolecular Engineering, The Ohio State University, Columbus, OH, United States, ${ }^{4}$ Department of Radiation \\ Oncology, University of Texas Southwestern Medical Center, Dallas, TX, United States
}

\section{OPEN ACCESS}

Edited by:

Wuqiang Zhu,

Mayo Clinic in Arizona, United States

Reviewed by:

Mahmood Khan,

College of Medicine, The Ohio State

University, United States

Yun Chang,

Purdue University, United States

Yi Hong,

University of Texas at Arlington,

United States

*Correspondence:

Yifan Ma

ma.1711@buckeyemail.osu.edu

Zhaogang Yang

Zhaogang.Yang@UTSouthwestern.edu

Jingjing Zhang

zhang.8211@osu.edu

Specialty section:

This article was submitted to

Nanobiotechnology,

a section of the journal

Frontiers in Bioengineering and

Biotechnology

Received: 21 March 2020

Accepted: 04 May 2020

Published: 05 June 2020

Citation:

Shi C, Xie H, Ma Y, Yang Z and

Zhang J (2020) Nanoscale

Technologies in Highly Sensitive

Diagnosis of Cardiovascular Diseases.

Front. Bioeng. Biotechnol. 8:531.

doi: 10.3389/fbioe.2020.00531
Cardiovascular diseases (CVD) are the leading cause of death and morbidity in the world and are a major contributor to healthcare costs. Although enormous progress has been made in diagnosing CVD, there is an urgent need for more efficient early detection and the development of novel diagnostic tools. Currently, CVD diagnosis relies primarily on clinical symptoms based on molecular imaging (MOI) or biomarkers associated with CVDs. However, sensitivity, specificity, and accuracy of the assay are still challenging for early-stage CVDs. Nanomaterial platform has been identified as a promising candidate for improving the practical usage of diagnostic tools because of their unique physicochemical properties. In this review article, we introduced cardiac biomarkers and imaging techniques that are currently used for CVD diagnosis. We presented the applications of various nanotechnologies on diagnosis within cardiac immunoassays (CIAs) and molecular imaging. We also summarized and compared different cardiac immunoassays based on their sensitivities and working ranges of biomarkers.

Keywords: cardiovascular disease (CVD), biomarker, molecular imaging, diagnostic, nanotechnology

\section{INTRODUCTION}

Cardiovascular diseases (CVDs) are the most common causes of death in the world (Ho, 2018). CVDs can be medically defined as a group of disorders involving heart, brain, and blood vessels, including but not limited to coronary heart diseases, peripheral arterial diseases, rheumatic heart diseases, deep vein thrombosis, and cerebrovascular diseases - all of which result in ischemia and tissue death (Yang et al., 2009, 2012; Laflamme et al., 2012; Chakrabarti et al., 2013; Yu et al., 2015; Fan et al., 2020a,b). General CVDs can be characterized into five categories: atherosclerosis, acute myocardial infarction (AMI), heart failure (HF), stroke, and hypertension (Lichtenstein and Matthan, 2007; Govindappa et al., 2020; Joshi et al., 2020). Individuals who demonstrate tobacco smoking, high levels of low-density lipoproteins (LDL)-associated cholesterol, glucose, and diabetes as well as overweight and obesity, are especially susceptible to CVD morbidity and mortality (D'Agostino et al., 2008). Effectively diagnosing individuals who are most susceptible to CVDs opens the door to optimal treatment, thereby lowering the death rate. Given that early-stage CVDs demonstrate a high survival rate, predicting CVDs early on is essential.

Current common clinical CVD diagnosis methods include electrocardiography (ECG), plain $\mathrm{X}$-ray, computed tomography (CT), and magnetic resonance imaging (MRI), and other MOI 
techniques (Anderson et al., 2013). ECG measures variations in the conduction system of the heart and monitors chest pain in AMI patients (Fesmire et al., 1998). CT scans X-ray images around the body and generates slices images of bones, blood vessels and tissues, which is appropriate for CVD diagnosis on grounds of its high signal contrast and accuracy (Kirkpatrick et al., 2003). MRI has been widely used in atherosclerosis and stroke detection given it scans three-dimensional images of bodies in a non-invasive manner (Pykett et al., 1983). However, these traditional methods were limited to low sensitivity and specificity.

To overcome these aforementioned difficulties, various new platforms such as cardiac immunoassays (CIAs) and advanced molecular imaging (MOI) were introduced, which significantly improved the efficiency of CVD diagnosis over the past decades (Qureshi et al., 2012; Osborn and Jaffer, 2013). Cardiac biomarkers are substances in the blood when the heart and brain are damaged or act abnormally. For example, cardiac troponin I (cTnI) has been demonstrated as a promising biomarker for AMI (Apple et al., 1997). MOI is capable of identifying cellular and molecular biology process, however, each technique has advantages and limitations. Therefore, advanced MOI combined different MOI techniques have been invented (e.g., dual-module, triple-module-CT) to obtain more detailed imaging information, which has increased the accuracy of diagnostic results (Hur et al., 2011, 2012).

Despite the great merits of previous methods, early-stage diagnosis is still challenging due to its complex pathophysiology, vague symptoms, and low expression levels of cardiac biomarkers. These difficulties increase the aggravation and mortality of CVDs. For instance, atherosclerosis shows no signs or symptoms and extremely low-level of related biomarkers in some patients even after a heart attack (Libby, 2002). Moreover, quick and convenient measurements are inadequate in addressing the expanded needs of CVD patients. Hence, rapid, accurate, and highly sensitive and specific platforms are needed for early-stage CVDs.

Nanotechnology involves nanoscale dimension systems (Johnson, 2012; Zhou et al., 2014), has specific physicochemical properties that make them appealing for improving current diagnosis (Kuriyama et al., 2011; Sun et al., 2016, 2019; Chen Z. et al., 2017; Liu et al., 2017; Yang et al., 2020a). Nanomaterials have been extensively applied to CIAs, including electrochemiluminescence (ECL), Electrochemical (EC), and photoelectrochemistry (PEC) due to their unique optical property, electrical property, and excellent biocompatibility (Figure 1) (Abdorahim et al., 2016). For example, Gold nanoparticles (AuNPs) can be incorporated with biotinylated antibodies to reduce non-specific binding, or conjugated with biomolecules with specific physical properties [e.g., hybridization chain reaction (HCR)] for signal amplification. Liu G. et al. (2016) detected cTnI via antigen-antibody affinity with a low limit of detection using AuNPs and graphene oxide. AuNPs and other metal nanoparticles can modify substrates (e.g., boron nitride nanosheets, titanium) in EC assays as well because of their attractive electrical properties (Golberg et al., 2010). Other nanomaterials, like silica/Pt NPs, are common signal enhancers in PEC and surface plasmon resonance (SPR) thanks to their efficient photocurrent quenching ability and unique plasmonic properties (Homola et al., 1999). Besides, upconversion nanoparticles (UCNPs) have been used in fluorescence assay because of their excellent photon conversion ability (Haase and Schäfer, 2011). Also, knotted and hollow nanomaterials (e.g., nanosheets, nanotubes, nanowires, and nanoclusters) with the large surface area that increases loading efficiency of biomolecules for signal enhancement (Kong et al., 2000). Nanomaterials also play important roles in MOI. Nanomaterials coupled with photoacoustic, fluorescent, radioactive, paramagnetic substances can work as contrast agents in MOI settings to enhance their detection signal (Van Schooneveld et al., 2010).

In this review, we will introduce the recent progress of nanotechnology for diagnosing CVDs. The nanotechnology facilitated CIA and MOI applications will be covered. Firstly, we summarized common clinical cardiac biomarkers and MOI settings. Then the applications on nanotechnology to identify cardiac biomarkers within different platforms based on unique properties of various nanomaterials will be introduced, including ECL, fluorescence, PEC, EC Surface-enhanced Raman scattering (SERS), SPR, Field effect transistor (FET), Enzyme-Linked Immunosorbent Assay (ELISA), and lateral flow assay (LFA). We compared different CIAs based on their sensitivities and working ranges of cardiac biomarkers as well. Besides, we concluded current diagnosis achievements on MOI with the help of functionalized nanoparticle.

\section{CVD DIAGNOSTIC SETTINGS}

\section{Cardiac Immunoassay (CIA)}

Cardiac biomarkers present in human bodyfluids are reliable and reproducible indicators of the risk and progression of CVDs. They can be detected and quantified through various CIAs based on antigen-antibody immunoaffinity. Measuring expression levels of cardiac biomarkers within CIAs shows advantages, including high sensitivity, rapid, cheap, and non-invasive for the prediction and diagnosis of disease. Cardiac biomarkers can be classified as circulating biomarkers and exosomal biomarkers. Circulating biomarkers present in bodyfluids freely, and exosomal biomarkers are bound into or on the surface of extracellular vesicles (EVs) that are mobile and secreted from cells.

\section{Cardiac Circulating Biomarkers}

Circulating biomarkers include miRNA, mRNA, long-noncoding RNA, proteins, and other substances that present in human blood, milk, saliva, urine, and cerebral spinal biofluids (Durrani-Kolarik et al., 2017; Wang et al., 2017a,b; Wang X. et al., 2018; Yang et al., 2020b). Currently, several cardiac biomarkers, such as cardiac troponin I (cTnI), troponin I (TnI), myoglobin $(\mathrm{MB}), \mathrm{C}$-reactive protein (CRP), and creatine kinase-MB (CK$\mathrm{MB})$, have attracted interests as potential biomarkers for AMI (Christenson and Christenson, 2013). Particularly, cTnI has high specificity and sensitivity toward AMI (Jo et al., 2015), and MB is a good candidate for early diagnosis of AMI (Korff et al., 2006). 


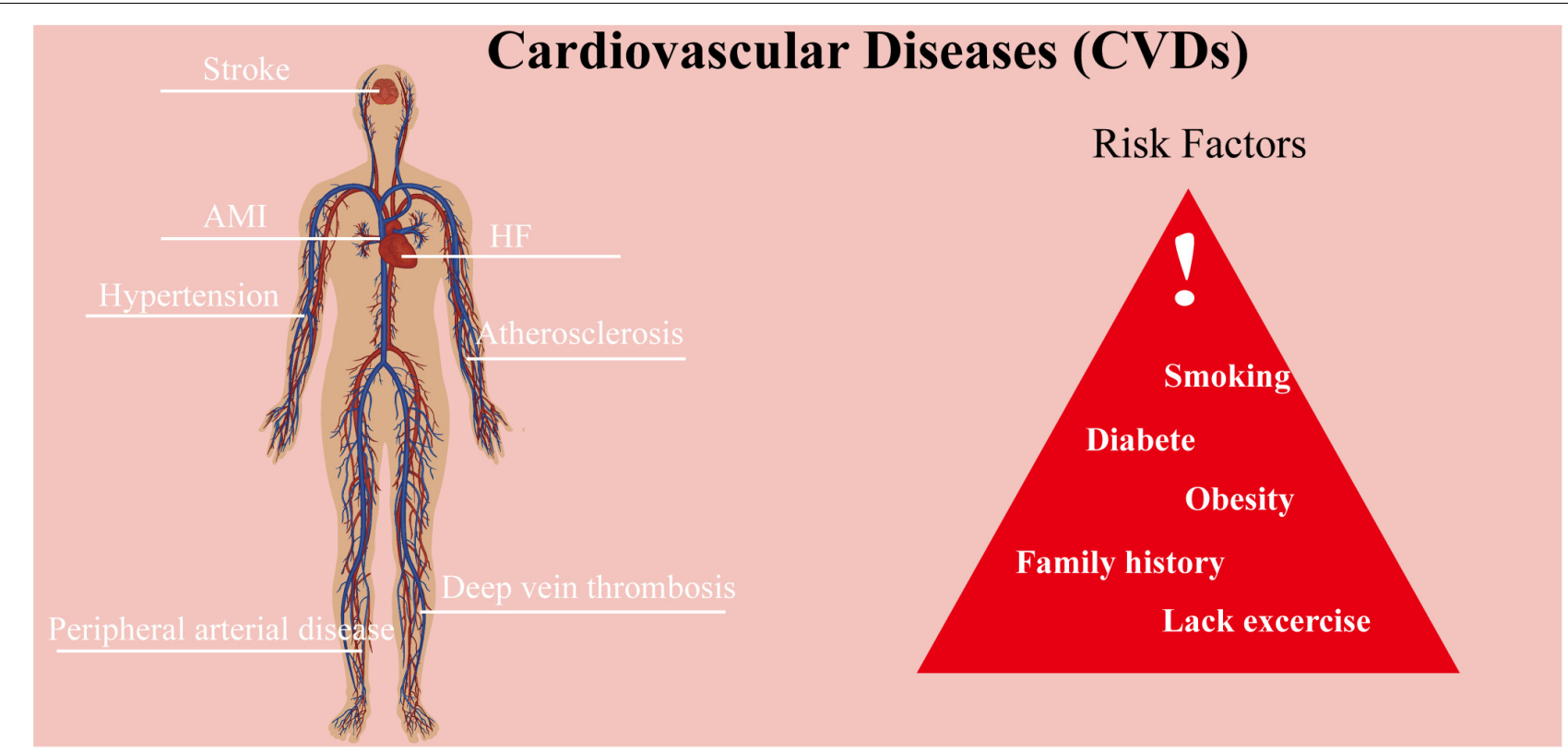

\section{Diagnosis}

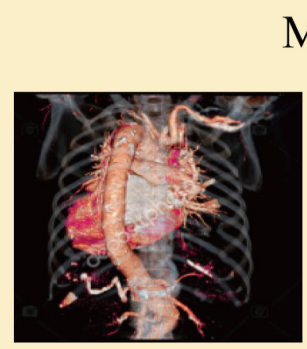

CT

SPECT

MRI

PET

CMR
Molecular Imaging

\section{Nanotechnology Platform}

Cardiac Biomarker

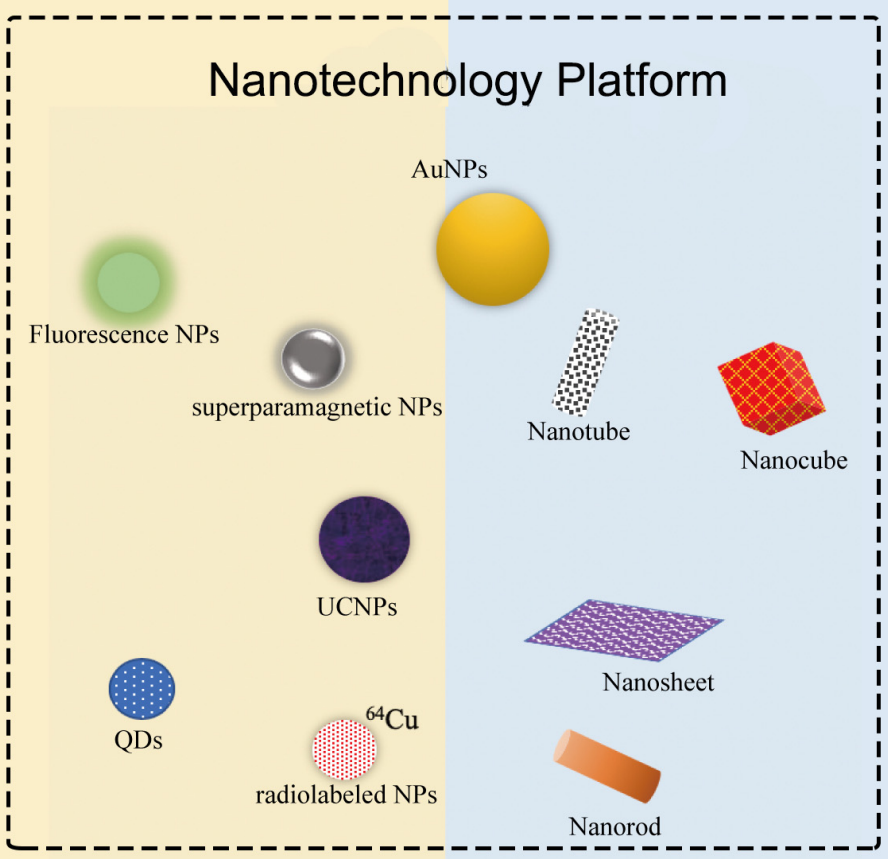

$\mathrm{Ab}_{2}$

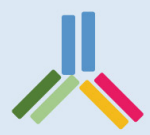

cTnI

$\mathrm{Mb}$

CK-MB

NT-proBNP

miR-133

miR1

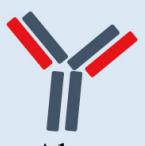

$\mathrm{Ab}_{1}$

FIGURE 1 | Cardiovascular diseases (CVDs), their risk factors, and their diagnosis settings include molecular imaging and cardiac immunoassay within the nanotechnology platform. A $b_{1}$, capture antibodies that immobilize the targets. A $b_{2}$, detection or secondary antibodies that detect and quantify the targets.

Myeloperoxidase (MPO), glycogen phosphorylase isoenzyme BB (GPBB), B-type natriuretic peptide (BNP), N-terminal pro-Btype natriuretic peptide (NT-proBNP), C-type natriuretic peptide (c-TNP), Matrix metalloproteinase-8 (MMP-8), MMP-9 and tissue inhibitor of MMP-8 (TIMP-1), and leukotriene B4 are promising biomarkers as well (Anderon, 2005).
Recently, researchers discovered that some miRNAs circulating in serum or plasma were closely correlated with CVDs. For example, miR-208 was undetectable in healthy donors but was detected successfully in $90.9 \%$ of AMI patients (Ji et al., 2009). There are almost 50 circulating miRNAs proven to be relevant to CVDs. Specifically, miR-208a, miR-208b, and 
miR133 are up-regulated AMI biomarkers, while miR150, let-7b, and miR-126 are down-regulation AMI biomarkers (Corsten et al., 2010; Wang et al., 2010; Gidlöf et al., 2011; Long et al., 2012a,b; Devaux et al., 2013; Friese et al., 2013; Li et al., 2013). Furthermore, miR-423, miR-18b, miR-499, miR-142, miR-320a, miR-22, miR-20b, and miR-26b are positively associated with HF, but miR-103 is shown to be low in HF patients (Corsten et al., 2010; Tijsen et al., 2010; Goren et al., 2012; Ellis et al., 2013; Marfella et al., 2013). Additionally, let-7e, Hcmv-miR-UL112, miR-605, miR623, miR-516b, miR-132 are found to be relatively high in plasma in hypertension cases. In contrast, miR-296, miR-133b, miR-625, miR-1236 are down-regulation biomarkers (Li et al., 2011). Moreover, miR-145, miR21 are up-regulating biomarkers for strokes, and miR-221, miR-210, miR-30a, and miR-126 are shown to be low in human blood in stroke cases (Zeng et al., 2011; Gan et al., 2012; Long et al., 2012b; Tsai et al., 2013). In summary, circulating miRNAs are relatively stable and serve as sufficiently sensitive biomarkers for CVD diagnosis.

\section{Cardiac Exosomal Biomarkers}

EVs are submicron-sized vesicles ranging from 30 to $1000 \mathrm{~nm}$ secreted by cells. EVs play important roles in transferring proteins, mRNA, miRNA, and other molecules among cells (Yang et al., 2016; Ma et al., 2019; Walters et al., 2019; Liu et al., 2019). Increasing evidence showed that exosomal miRNAs are involved in the pathogenesis of CVDs (Zamani et al., 2019). It has been observed that exosomal miRNAs mediate intercellular communication in cardiovascular systems and play an indispensable role in the control of cellular functions (Bang et al., 2014). As such, exosomal miRNAs can be used as biomarkers for diagnosing subjects with CVDs (Rehman et al., 2017).

Recently, researchers found miR-1, miR-133a, miR-21, and miR-499 are AMI-related biomarkers (Cheng et al., 2012; Oerlemans et al., 2012). Also, miR-192, miR-194, miR-34a, miR423-5p, miR320a, miR-22, and miR-92b are highly associated with HF (Goren et al., 2012; Matsumoto et al., 2013). Besides, miR-223 isolated from serum EVs is a potential biomarker for stroke (Chen Y. et al., 2017). Additionally, exosomal membrane proteins or internal proteins, such as TNF- $\alpha$ and fibronectin are also potential CVD biomarkers (de Jong et al., 2012; Yu et al., 2012). Table 1 summarized the biomarkers mentioned above.

\section{Molecular Imaging}

Molecular imaging (MOI) is a common diagnostic tool for CVD in clinical practice. When paired with other approaches, MOI can reveal individual biology, including blood vessels, the brain, and the heart (Jaffer et al., 2007). Common MOI approaches include photoacoustic tomography (PAT), MRI, CT, positron emission tomography (PET), and single photon emission computed tomography (SPECT). PAT utilizes the photoacoustic effect that converts optical adsorption into acoustic energy and generates high-resolution imaged under optically ballistic and diffusive modules (Xia et al., 2014). Various materials such as dyes, nanoparticles, and probes can work as functional contrasts in PAT for vascular imaging (Li and Wang, 2009). CT takes $\mathrm{X}$-ray images from different angles around the human body and produces cross-sectional images of the body to reveal blood vessels, tissues and organs (Article, 2018). MRI generates anatomical images based on the changes of protons in the body with a strong magnetic field (Hashemi et al., 2012). MRI sensors first turn on the radiofrequency current that spins the protons out of equilibrium and then detects the time and amount of released energy of realigning randomized protons within the magnetic field after turning off the radiofrequency current (McRobbie et al., 2017). Detected parameters are translated into images for diagnosis. PET uses injected radioactive tracers to review and evaluate tissues. The radiotracers used in PET produce positrons after decaying. Positrons react with electrons and produce photons that aggregate in specific, disease-related areas of the human body (Shan et al., 2013). The combination of PET with CT or MRI can create detailed, specific images. Similar to PET, SPECT provides tomographic images by recording and translating the activities of radioactive tracers that have gamma ray emissions (Hutton, 2014).

\section{NANOTECHNOLOGY-BASED CARDIAC IMMUNOASSAY}

Various advanced techniques like ECL, PEC, SERS, SPR, and ELISA have been utilized to detect cardiac biomarkers with precision. Despite satisfactory results from previous methods, pursuing high sensitivity and accuracy in testing results is still an ongoing endeavor. Combining nanotechnologies with cardiac immunoassays may serve as a solution for early-stage CVD diagnosis. Nanotechnologies may reduce non-specific binding sites, provide high binding efficiency of cardiac targets, offer excellent signal amplification, and possess multiple functions. Table 2 summarized and compared performances of recent cardiac immunoassays based on various nanotechnology platforms.

\section{Electrochemiluminescence (ECL) Immunoassay}

Electrochemiluminescence (ECL) involves electron-transfer reactions that generate excited states and light emission, thus works as a common diagnostic assay to quantify expression levels of biomarkers because detected emission intensity in ECL is proportional to the concentration of the biomarkers (Richter, 2004). Luminol is one of the most important signal enhancers in ECL but has a weak signal and poor solubility. Fortunately, luminol-functionalized nanomaterials can overcome the limitations of traditional luminol and greatly enhance the intensity and sensitivity due to their large specific surface area (e.g., carbon nanotubes, nanosheets), the ability to functionalize signal amplification materials (e.g., nucleic acid isothermal amplification, HCR signal amplification), conductivity, and surface charge. All of these advantages have contributed to intense attention of ECL assay in biomolecule analysis (Hao et al., 2014; Feng et al., 2016).

Dong et al. (2019) detected NT-proBNP using ECL immunoassay based on ECL resonance energy transfer (RET). The ECL-RET transfer was between semicarbazide-modified 
TABLE 1 | Summary of cardiac biomarkers.

\begin{tabular}{|c|c|c|c|c|}
\hline Biomarker ID & Type & Pathology & Expression & References \\
\hline $\begin{array}{l}\text { cTnl, Tnl, MB, C-CRP, CK-MB, MPO, GPBB, } \\
\text { NT-proBNP, c-TNP, MMP-8, MMP-9, TIMP-1, } \\
\text { leukotriene B4, TNF- } \alpha \text {, and fibronectin }\end{array}$ & Protein & $\begin{array}{l}\text { AMI, HF, } \\
\text { Hypertension, } \\
\text { Stroke }\end{array}$ & Upregulated & $\begin{array}{l}\text { Anderon, 2005; Korff et al., 2006; de Jong et al., 2012; Yu } \\
\text { et al., 2012; Christenson and Christenson, 2013; Jo et al., } 2015\end{array}$ \\
\hline $\begin{array}{l}\text { miR-208, miR-208a, miR-208b, miR133, } \\
\text { miR-1, miR-133a, miR-21, and miR-499 }\end{array}$ & RNA & AMl & Upregulated & $\begin{array}{l}\text { Ji et al., 2009; Corsten et al., 2010; Wang et al., 2010; Gidlöf } \\
\text { et al., 2011; Cheng et al., 2012; Long et al., 2012a,b; } \\
\text { Oerlemans et al., 2012; Devaux et al., 2013; Friese et al., 2013; } \\
\text { Li et al., } 2013\end{array}$ \\
\hline miR150, let-7b, and miR-126 & RNA & AMl & Downregulated & Devaux et al., 2013; Friese et al., 2013; Li et al., 2013 \\
\hline $\begin{array}{l}\text { miR-423, miR-18b, miR-499, miR-142, } \\
\text { miR-320a, miR-22, miR-20b, miR-26b, } \\
\text { miR-192, miR-194, miR-34a, miR-423-5p, } \\
\text { miR320a, miR-22, and miR-92b }\end{array}$ & RNA & HF & Upregulated & $\begin{array}{l}\text { Corsten et al., 2010; Tijsen et al., 2010; Goren et al., 2012; Ellis } \\
\text { et al., 2013; Marfella et al., 2013; Matsumoto et al., } 2013\end{array}$ \\
\hline miR-103 & RNA & $\mathrm{HF}$ & Downregulated & Ellis et al., 2013 \\
\hline $\begin{array}{l}\text { let-7e, Hcmv-miR-UL112, miR-605, miR623, } \\
\text { miR-516b, miR-132 }\end{array}$ & RNA & Hypertension & Upregulated & Li et al., 2011 \\
\hline miR-296, miR-133b, miR-625, miR-1236 & RNA & Hypertension & Downregulated & Li et al., 2011 \\
\hline miR-145, miR21, miR-223 & RNA & Stroke & Upregulated & $\begin{array}{l}\text { Zeng et al., 2011; Gan et al., 2012; Long et al., 2012b; Tsai } \\
\text { et al., 2013; Chen Y. et al., } 2017\end{array}$ \\
\hline miR-221, miR-210, miR-30a, and miR-126 & RNA & Stroke & Downregulated & Zeng et al., 2011; Long et al., 2012b \\
\hline
\end{tabular}

gold nanoparticles (AgNC-sem@AuNPs) covered nanocubes (donor) and a Ti (IV)-based metal-organic framework of type MIL-125 (receptor). The partial overlap between the ECL emission of the AgNC-sem@AuNPs and the visible adsorption spectrum of MIL-135 created RET. The schematic was illustrated in Figure 2A. Firstly, $8 \mu \mathrm{L}$ of AgNC-sem@AuNP solution was dropped on the pre-cleaned glassy carbon electrode (GCE) surface, then the primary antibody ${ }_{1}\left(\mathrm{Ab}_{1}\right)$ was immobilized on it via $\mathrm{Au}-\mathrm{NH}_{2}$ bond. Then, NT-proBNP analytes were added to the assay and captured by $\mathrm{Ab}_{1}$. Finally, the MIL-125 labeled secondary antibody $2\left(\mathrm{Ab}_{2}\right)$ was incubated onto the electrode to form the sandwich format and quench the ECL strength of luminophore. The assay was able to recover $96.8 \% \sim 100.2 \%$ of NT-proBNP and detect it as low as $0.11 \mathrm{pg} / \mathrm{mL}$.

Zhu et al. (2019) detected cTnI using Au Nanocluster and HCR signal amplification. A sandwich immunocomplex composed of $c T n I, A b_{1}$, and $\mathrm{Ab}_{2}-\mathrm{AuNP}-\mathrm{T}_{1}$ was applied. $\mathrm{Ab}_{2}$ AuNP- $\mathrm{T}_{1}$ is a smart probe in which the DNA initiator strands $\left(\mathrm{T}_{1}\right)$ and $\mathrm{Ab}_{2}$ are conjugated onto the AuNPs. The schematic was illustrated in Figure 2B. Once the cTnI was caught, the initiator strands $\mathrm{T}_{1}$ of $\mathrm{Ab}_{2}-\mathrm{AuNP}-\mathrm{T}_{1}$ opened the hairpin DNA structures ( $\mathrm{H} 1$ and $\mathrm{H} 2$ ) that were dual-labeled on the Au nanoclusters (Au NCs). This process triggered hybridization events, thus modified a large number of Au NCs on the surface of the electrode. Finally, a strong ECL signal was emitted owing to the reaction of the modified $\mathrm{Au}$ NCs and the coreactant $\mathrm{K}_{2} \mathrm{~S}_{2} \mathrm{O}_{2}$. This ECL-HCR sensor was able to detect $1.01 \mathrm{fg} / \mathrm{mL}$ cTnI with high specificity stability and reproducibility.

Recently, various research groups have made great progress in CVD diagnosis using ECL assay. Wang et al. (2019) combined $\mathrm{Co}^{2+}$-based metal organic frameworks (MOF), zeolitic imidazolate frameworks (ZIF-67), and luminol-capped $\mathrm{Ag}$ nanoparticles (luminol-AgNPs) for fast and ultrasensitive detection of cTnI, with a $0.58 \mathrm{fg} / \mathrm{mL}$ detection limit. Zou et al. (2019) developed an ECL immunosensor to detect MB in human serum. They fabricated a basal electrode using AuNPs and platinum nanowires that were deposited onto indium tin oxide-coated glass linked with 3-aminopropyl-trimethoxysilane. Besides, Adhikari et al. (2019) presented an ultrasensitive labelfree ECL immunosensor for CK-MB detection using a novel nanocomposite-modified printed electrode. To fabricate this sensor, carbon nano-onions (CNOs) $/ \mathrm{Fe}_{3} \mathrm{O}_{4} / \mathrm{AuNP} /$ chitosan (CS) nanocomposite was dropped in single-layered rolled-up carbon nanotubes (SWCNTs). Then $\mathrm{Ab}_{1}$ against $\mathrm{CK}-\mathrm{MB}$ was spiked onto the electrode and blocked by bovine serum albumin (BSA). Once CK-MB was captured on the electrode, the ECL signal was determined by Tris(2,2'-bipyridyl)-ruthenium(II) chloride $\left(\left[\mathrm{Ru}(\mathrm{bpy})_{3}\right]^{2+} \mathrm{Cl}\right)$ and tri- $n$-propylamine $(\mathrm{TPr} \mathrm{A})$, in which $\left.\mathrm{Ru}(\mathrm{bpy})_{3}\right]^{2+} \mathrm{Cl}$ was used as luminophore and $\operatorname{TPrA}$ was the co-reactant. Moreover, Lakshmanakumar et al. (2019) functionalized graphene quantum dots with acetic acid (fGQDs) on the Au electrode to detect cTnI. The cTnI was recognized via carbodiimide conjugation between the $\mathrm{N}-\mathrm{H}$ group of $\mathrm{cTnI}$ and the $\mathrm{COOH}$ group on fGQDs instead of antibody-antigen interaction. The interaction of cTnI and fGQDs was examined by cyclic voltammetry (CV) and amperometry (Lakshmanakumar et al., 2019). They detected cTnI over a linear range of 0.17$3 \mathrm{ng} / \mathrm{mL}$ and offered a detection limit of $0.02 \mathrm{ng} / \mathrm{mL}$ with good stability and sensitivity. Based on the aforementioned discussion, ECL immunoassay is appealing for diagnosis since its high stability as well as sensitivity and specificity. Despite the considerable advantages for biomedical analysis, ECL often requires specialized and expensive equipment for generating excited states with light-emitting for detection, which to some extent impair its extensive application.

\section{Fluorescence Immunoassay}

Fluorescence immunoassay is by far the dominant analytical approach in biomedical engineering on account of its outstanding versatility and signal enhancement ability (Strianese et al., 2012). 
TABLE 2 | Comparison of cardiac biomarker detection in developed immunoassays.

\begin{tabular}{|c|c|c|c|c|c|}
\hline Target & Assay & Nanoplatform & Range & Detection limit & References \\
\hline \multirow[t]{24}{*}{ cTnl } & ECL & Au nanocluster & $5 \mathrm{fg} / \mathrm{mL}$ to $50 \mathrm{ng} / \mathrm{mL}$ & $1.01 \mathrm{fg} / \mathrm{mL}$ & Zhu et al., 2019 \\
\hline & ECL & Ag Nanoparticles & NA & $0.58 \mathrm{fg} / \mathrm{mL}$ & Wang et al., 2019 \\
\hline & ECL & QDs & $0.17-3 \mathrm{ng} / \mathrm{mL}$ & $0.02 \mathrm{ng} / \mathrm{mL}$ & Lakshmanakumar et al., 2019 \\
\hline & Fluorescence & QDs & $1 \mathrm{pg} / \mathrm{mL}$ to $10 \mathrm{ng} / \mathrm{mL}$ & $0.227 \mathrm{pg} / \mathrm{mL}$ & Miao et al., 2019 \\
\hline & Fluorescence & Pd-Ir nanocubes & $1 \mathrm{pg} / \mathrm{mL}$ to $1 \mathrm{ng} / \mathrm{mL}$ & $0.31 \mathrm{pg} / \mathrm{mL}$ & Tan et al., 2019 \\
\hline & Fluorescence & AuNP & NA & $0.019 \mathrm{ng} / \mathrm{mL}$ & Han and Kim, 2019 \\
\hline & PEC & QDs & $0.5 \mathrm{pg} / \mathrm{mL}$ to $10 \mathrm{ng} / \mathrm{mL}$ & $0.5 \mathrm{pg} / \mathrm{mL}$ & Xue et al., 2019 \\
\hline & PEC & Nanospheres and QDs & $0.08 \mathrm{ng} / \mathrm{mL}$ to $40 \mathrm{ng} / \mathrm{mL}$ & $0.026 \mathrm{ng} / \mathrm{mL}$ & Dong et al., 2020 \\
\hline & PEC & Mesoporous silica nanoparticles & $1.2 \mathrm{fg} / \mathrm{mL}$ to $20 \mathrm{ng} / \mathrm{mL}$ & $0.47 \mathrm{fg} / \mathrm{mL}$ & Gao et al., 2019 \\
\hline & EC & AuNPs & $1-1100$ pM & $0.18 \mathrm{pM}$ & Lopa et al., 2019 \\
\hline & EC & Carbon nanotubes & NA & $0.05 \mathrm{ng} / \mathrm{mL}$ & Vasantham et al., 2020 \\
\hline & EC & Nanospheres & $0.005 \mathrm{ng} / \mathrm{mL}$ to $100 \mathrm{ng} / \mathrm{mL}$ & $5 \mathrm{pg} / \mathrm{mL}$ & Singh et al., 2019 \\
\hline & EC & Carbon nanotubes & $0.05 \mathrm{ng} / \mathrm{mL}$ to $30 \mathrm{ng} / \mathrm{mL}$ & $0.03 \mathrm{ng} / \mathrm{mL}$ & Shen et al., 2019 \\
\hline & EC & Nanorods & $0.01 \mathrm{ng} / \mathrm{mL}$ to $10 \mathrm{ng} / \mathrm{mL}$ & NA & Sandil et al., 2019 \\
\hline & EC & Nanocubes & NA & $33.3 \mathrm{fg} / \mathrm{mL}$ & Zhang et al., 2019 \\
\hline & EC & Nanoparticles & $1.0 \mathrm{pg} / \mathrm{mL}$ to $100 \mathrm{ng} / \mathrm{mL}$ & $0.39 \mathrm{pg} / \mathrm{mL}$ & Ma et al., 2019 \\
\hline & EC & Nanocubes & $100 \mathrm{fg} / \mathrm{mL}$ to $250 \mathrm{ng} / \mathrm{mL}$ & $33 \mathrm{fg} / \mathrm{mL}$ & Lv et al., 2019 \\
\hline & SERS & AuNPs & $0.01 \mathrm{ng} / \mathrm{mL}$ to $1000 \mathrm{ng} / \mathrm{mL}$ & $5 \mathrm{pg} / \mathrm{mL}$ & Fu et al., 2019 \\
\hline & SPR & AuNPs & NA & $3.75 \mathrm{ng} / \mathrm{mL}$ & Chen et al., 2019 \\
\hline & FET & Nanoribbon & NA & $1 \mathrm{pg} / \mathrm{mL}$ & Liu Q. et al., 2016 \\
\hline & ELISA & Nanodendrites & $0.1 \mathrm{pg} / \mathrm{mL}$ to $1000 \mathrm{ng} / \mathrm{mL}$ & $0.056 \mathrm{pg} / \mathrm{mL}$ & Jiao et al., 2019 \\
\hline & LFA & AuNPs & NA & $0.1 \mathrm{ng} / \mathrm{mL}$ & Lim et al., 2019 \\
\hline & LFA & Nanosphere & $0.049 \mathrm{ng} / \mathrm{mL}$ to $50 \mathrm{ng} / \mathrm{mL}$ & $0.049 \mathrm{ng} / \mathrm{mL}$ & Lou et al., 2019a \\
\hline & LFA & Nanosphere & & $0.1 \mathrm{ng} / \mathrm{mL}$ & Lou et al., 2019b \\
\hline NT-proBNP & ECL & Nanocube and AuNPs & $0.25 \mathrm{pg} / \mathrm{mL}$ to $100 \mathrm{ng} / \mathrm{mL}$ & $0.11 \mathrm{pg} / \mathrm{mL}$ & Dong et al., 2019 \\
\hline \multirow[t]{3}{*}{$\mathrm{MB}$} & ECL & AuNPs and platinum nanowires & $3.0 \mathrm{ng} / \mathrm{mL}$ to $0.32 \mu \mathrm{g} / \mathrm{mL}$ & $0.11 \mathrm{ng} / \mathrm{mL}$ & Zou et al., 2019 \\
\hline & Fluorescence & UCNPS & $10 \mathrm{ng} / \mathrm{mL}$ to $400 \mathrm{ng} / \mathrm{mL}$ & $0.21 \mathrm{ng} / \mathrm{mL}$ & Ji et al., 2019 \\
\hline & EC & AuNPs and nanosheets & $0.1 \mu \mathrm{g} / \mathrm{mL}$ to $100 \mu \mathrm{g} / \mathrm{mL}$ & $34.6 \mathrm{ng} / \mathrm{mL}$ & Adeel et al., 2019 \\
\hline cTnT & EC & Carbon nanotubes & $0.1 \mathrm{pg} / \mathrm{mL}$ to $8.0 \mathrm{pg} / \mathrm{mL}$ & $0.04 \mathrm{pg} / \mathrm{mL}$ & Phonklam et al., 2020 \\
\hline BNP & FET & Nanoribbon & & $10 \mathrm{pg} / \mathrm{mL}$ & Liu Q. et al., 2016 \\
\hline FABP & Fluorescence & Nanowires & $2.5-60 \mathrm{ng} / \mathrm{mL}$ & $1.36 \mathrm{ng} / \mathrm{mL}$ & Guo et al., 2019 \\
\hline \multirow[t]{4}{*}{ CK-MB } & ECL & AuNPs, $\mathrm{Fe}_{3} \mathrm{O}_{4}$, carbon nano-onions & $10 \mathrm{ng} / \mathrm{mL}$ to $50 \mathrm{fg} / \mathrm{mL}$ & $5 \mathrm{fg} / \mathrm{mL}$ & Adhikari et al., 2019 \\
\hline & SERS & AuNPs & NA & $9.7 \mathrm{pg} / \mathrm{mL}$ & Cheng et al., 2019 \\
\hline & FET & Nanoribbon & NA & $0.1 \mathrm{ng} / \mathrm{mL}$ & Liu Q. et al., 2016 \\
\hline & LFA & AuNPs & NA & $5 \mathrm{ng} / \mathrm{mL}$ & Lim et al., 2019 \\
\hline Vaspin & Fluorescence & UCNPS & $0.1 \mathrm{ng} / \mathrm{mL}$ to $55 \mathrm{ng} / \mathrm{mL}$ & $39 \mathrm{pg} / \mathrm{mL}$ & Ali et al., 2020 \\
\hline GPBB & LFA & AuNPs & NA & $10 \mathrm{ng} / \mathrm{mL}$ & Lim et al., 2019 \\
\hline
\end{tabular}

Nanomaterials have promoted the efficiency of fluorescence assay because nanomaterials have good solubility, low toxicity, and high binding affinity of biomolecules, which can couple with various intensive fluorescence materials for amplification (e.g., Horseradish Peroxidase) (Yeh et al., 2010; Lu et al., 2017).

Miao et al. (2019) used a robust nanoceria-linked immunosorbent assay to detect cTnI based on colorimetric and ratiometric fluorescence. Ratiometric fluorescence overcomes some dependence defects, such as external environment luminophore, consequently, it can be used for trace detection. The schematic of the sensor was illustrated in Figure 2C. After the bonding of $\mathrm{cTnI}$ and $\mathrm{Ab}_{1}, o$-phenylenediamine (OPD) as an organic substrate was oxidized and converted into 2,3-diaminophenazine (oxOPD) by the robust nanozyme of nanoceria with peroxidase-like properties and the addition of
$\mathrm{H}_{2} \mathrm{O}_{2}$. OxOPD was immobilized on the surface of g- $\mathrm{C}_{3} \mathrm{~N}_{4}$ QDs through hydrogen bonding and $\pi-\pi$ stacking interactions. The $g-\mathrm{C}_{3} \mathrm{~N}_{4}$ QDs led to a ratiometric fluorescence response as a result of photoinduced electron transfer (PET). Besides, a visible color change was detected through the conversion of colorless OPD to an orange oxOPD, which acted as a colorimetric fluorescence. As a result, cTnI was quantified by combining the merits of the ratiometric assay and colorimetric assay. Similarly, Tan et al. (2019) oxidized the OPD to oxOPD through the Pd-Ir nanocubes catalysis, which possessed excellent peroxidase-like activity. The detection range of cTnI was between $1 \mathrm{pg} / \mathrm{mL}$ to $1 \mathrm{ng} / \mathrm{mL}$, and the detection limit was $0.31 \mathrm{pg} / \mathrm{mL}$.

Moreover, Guo et al. (2019) completed multiplexed detection of cTnI, human heart-type fatty acid binding protein (FABP), and $\mathrm{MB}$ using Zinc Oxide Nanowires to enhance fluorescence signal. 


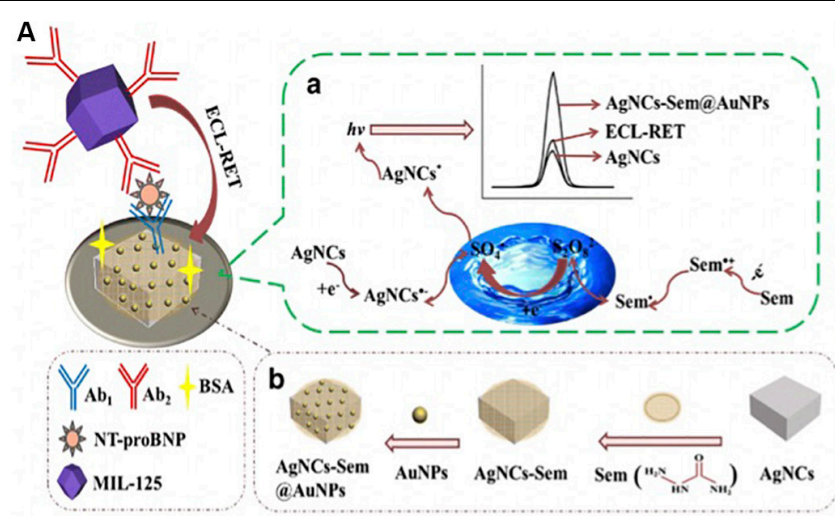

\section{B}
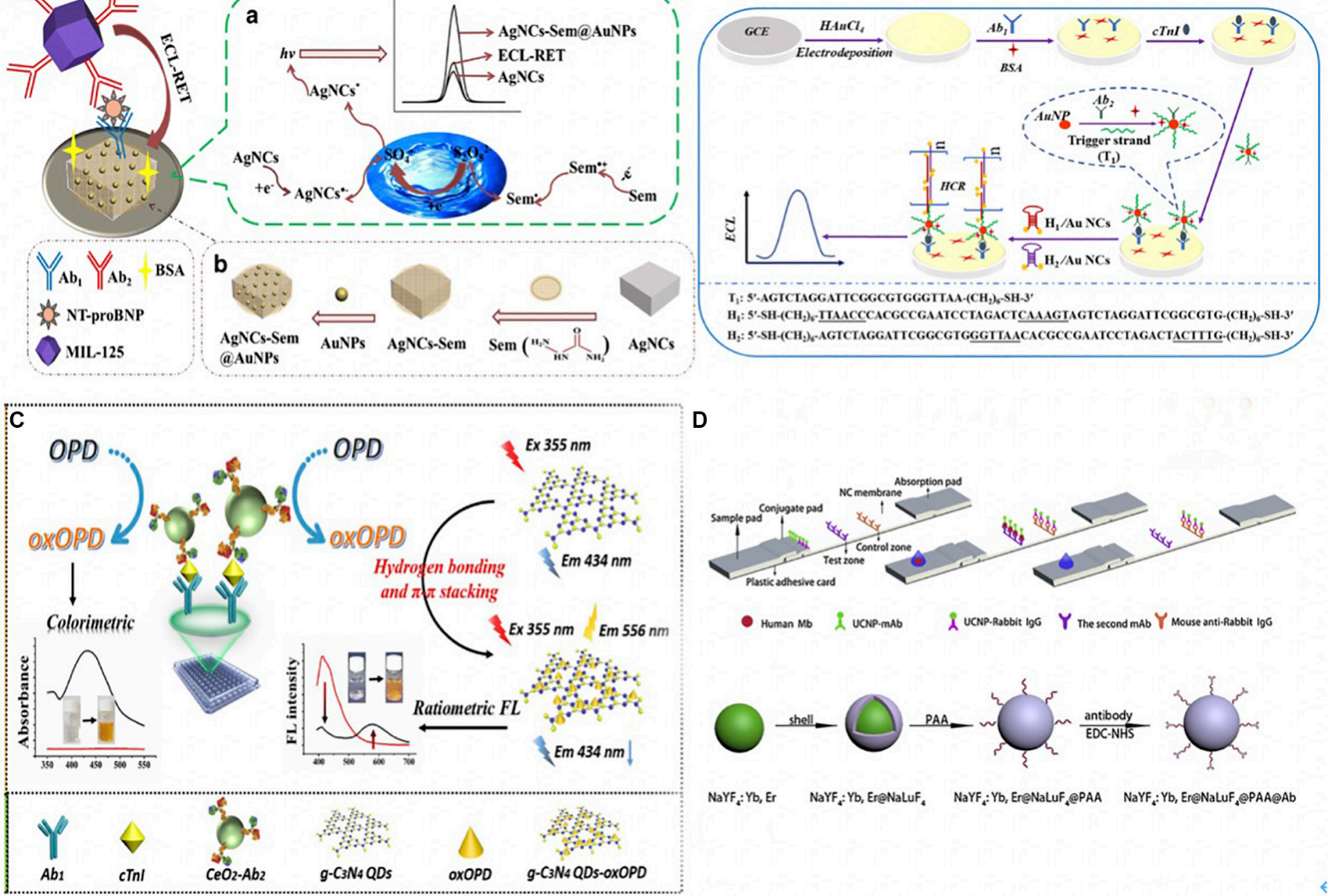

D
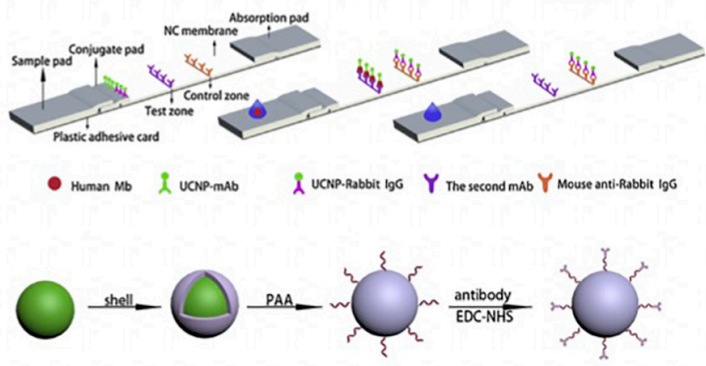

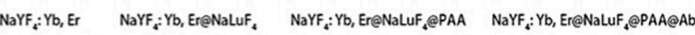

FIGURE 2 | (A) (a) The schematic of fabricating ECL immunoassay and its possible self-enhanced luminescence mechanism. A sandwich detection format was utilized to detect NT-proBNP. Ab 1 was immobilized via Au-NH 2 bond and dried on AgNC-sem@AuNP modified GCE surface, once the NT-proBNP was captured, the MIL-125 labeled $\mathrm{Ab}_{2}$ was added to quench the ECL luminophore. The resonance energy transfer was due to the partial overlap between the ECL emission of the AgNC-sem@AuNPs (wavelength 470-900 nm) and the visible adsorption spectrum of MIL-135 (wavelength 406-900 nm). (b) The preparation of self-enhanced luminophore AgNC-Sem@AuNPs. AuNPs combined with Sem-AgNCs with Au-NH $\mathrm{NH}_{2}$ bond. (Dong et al., 2019) Copyright 2020 Springer Nature Switzerland AG. (B) Schematic Illustration of ECL-HCR Immunosensor. AuNPs modified GCE immobilized Ab, via Au-N and Au-S bonds, and then AuNPs/GCE was prepared by electrodepositing in $\mathrm{HAuCl}_{4}$ solution. The $\mathrm{Ab}_{2}$-AuNP- $\mathrm{T}_{1}$ opened hairpin DNA structures ( $\mathrm{H} 1$ and $\mathrm{H} 2$ after cTnl was caught), which triggered hybridization that modified Au NCs on the electrode. Au NCs reacted with $\mathrm{K}_{2} \mathrm{~S}_{2} \mathrm{O}_{2}$ thus emitted the ECL signal (Zhu et al., 2019). Copyright 2020 American Chemical Society. (C). The mechanism of nanozyme-linked immunosorbent assay for dual colorimetric and ratiometric fluorescent detection. OPD was oxidized and converted into oxOPD by the robust nanozyme of nanoceria with peroxidase-like properties, resulting an emission maximum of oxOPD at $578 \mathrm{~nm}$. OxOPD was immobilized on the surface of $\mathrm{g}-\mathrm{C}_{3} \mathrm{~N}_{4}$ QDs, which led to a ratiometric fluorescence response as a result of photoinduced electron transfer (PET). The combination of ratiometric fluorescent assay with colorimetric assay could quantify cTnl (Miao et al., 2019). Copyright 2020 from Elsevier B.V. (D) Schematic of UCNPs based immunoassay and the synthesis,

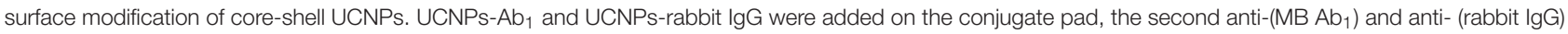
antibodies were separately stripped onto the NC membrane. Samples will be captured on the sample pad. UCNPs on the test and control line was excited by a continuous wave laser diode at $908 \mathrm{~nm}$ for reading. The Poly (acrylic acid) PAA was added to the core-shell NaYF 4 : Yb, Er@NaLuF 4 nanoparticles, and yield UCNPs@PAA particles. Then UCNPs@PAA were conjugated with Ab, using 1-Ethyl-3-(3-dimethyllaminopropyl) carbodiimide hydrochloride (EDC-HCl) and $\mathrm{N}$-Hydroxysulfosuccinimide sodium salt (Sulfo-NHS) as cross-linking agents (Ji et al., 2019). Copyright 2020 from Elsevier B.V.

Han and Kim (2019) designed a AuNP-Antibody-HRP conjugate for cTnI detection. They bound aldehydeactivated(ald)HRP and the primary amine group based on adsorption or covalent coupling, to enhance the sensitivity of the AuNPbased conjugates.

Upconversion nanoparticles (UCNPs) are another type of fluorescent nanomaterials that have been used in luminescent and fluorescent detection (Tan et al., 2016). Ji et al. (2019) used core-shell upconversion nanoparticles (UCNP) to capture the $\mathrm{MB}$ in blood samples. $\mathrm{MB}$ was fixed between UCNPs$A b_{1}$ and second anti-(MB $\left.A b_{1}\right)$ antibody to form a sandwich format. UCNPs were excited by a continuous wave laser diode at $908 \mathrm{~nm}$ for fluorescent reading by external equipment. The detailed procedure was illustrated in Figure 2D. Applied UCNPs increased the sensitivity of the assay, which reached a limit of detection as low as $0.21 \mathrm{ng} / \mathrm{mL}$ with a $90.6-110.5 \% \mathrm{MB}$ recovery rate (Ji et al., 2019). Ali et al. (2020) also designed a biosensor assisted with UCNPs for ultrasensitive detection of Vaspin.

\section{Photoelectrochemical (PEC)}

The photoelectrochemical (PEC) process refers to the electricity conversion of photons resulting from photoactive materials 
absorbing photons upon illumination and forming electronhole pairs. This, in turn, causes the oxidization-reduction reaction of the molecules and generates charge separation and subsequent charge transfer. PEC is a promising diagnostic tool since the detected photocurrent change is caused by the biological interactions between biomarkers and corresponding recognitions (Zhao et al., 2014). Nanomaterials have improved the sensitivity of PEC assay because they present a low background signal. For instance, AuNPs, QDs, $\mathrm{TiO}_{2}$ nanotubes (NTs), Pt NPs, and Silica NPs are suitable candidates for PEC biosensors thanks to their efficient photocurrent quenching ability and unique plasmonic properties (Zhao et al., 2012).

Xue et al. (2019) reported a split-type liposomal PEC immunoassay composed of immunoaffinity, cadmium sulfide (CdS) quantum dots-loaded liposomes (QDLL), and $\mathrm{TiO}_{2}$ nanotubes (NTs) that capture QDs for cTnI detection. The thioglycolic acid (TGA)-capped QDs and QDLL were linked with the $\mathrm{Ab}_{2}$ as signaling probes. The schema was explained in Figure 3A. cTnI was captured by $A_{1}$ in the 96well plates, and then QDLL-Ab $\mathrm{b}_{2}$ was introduced after the immunorecognition. Triton X-100 (10\%) was introduced to damage the QDLL and release the QDs that were later captured by the $\mathrm{TiO}_{2}$-NTs electrode. TGA-capped CdS QDs reacted with the Titania surface through the complexing between the carboxylic acid functionality on the CdS QDs and the hydroxyl groups of the $\mathrm{TiO}_{2} \mathrm{NTs}$ - via either chelating or bidentate binding modes (or both). Owing to the sensitization effect, the photocurrents were acquired for PEC immunoassay.

Similarly, Dong et al. (2020) modified the indium tin oxidepolyethylene terephthalate (ITO-PET) electrode with $\mathrm{Bi}_{2} \mathrm{Se}_{3}$ and the flower-like $\mathrm{ZnIn}_{2} \mathrm{~S}_{4}$ nanospheres (ZIS). The latter was synthesized by a solvothermal method, which accelerated the electronic transition and improved the photocurrent conversion efficiency. Additionally, the cadmium selenide (CdSe) QDs, which modified $\mathrm{Ab}_{2}$, were able to increase the photocurrent blocked by immunoaffinity binding. This resulted in a detection limit of $0.026 \mathrm{ng} / \mathrm{mL}$ of cTnI (Dong et al., 2020).

Gao et al. (2019) fabricated cellulose paper-based, singlecrystalline, three-dimensional aloe like $\mathrm{TiO}_{2}$ arrays (PSATs) as the electron transporting material. It was subsequently coupled with $\mathrm{CdS}$ to form PSATs/CdS to extend the solar spectrum response for cTnI detection (Figure 3B) (Gao et al., 2019). Single stranded DNAs (ssDNAs) that bound to cTnI specifically were coupled with positive-charged mesoporous silica nanoparticles (PMSNs). The complexes were prepared as the nanocarrier to entrap the $\mathrm{Cu}^{2+}$, which was regarded as a signal quencher because of its reaction with $\mathrm{CdS}$ to form $\mathrm{Cu}_{x} \mathrm{~S}$. After the formation of cTnIssDNAs complexes, $\mathrm{Cu}^{2+}$ formed $\mathrm{Cu}_{x} \mathrm{~S}$, which decreased the photocurrent signal. This process was used to quantify the concentration of cTnI.

Despite the accomplishments of PEC assay in CVD diagnosis, PEC assay has some disadvantages, especially the inherent drawback of photoanodes. For example, the CdS photoanodes of PEC might have low charge separation and transfer efficiency. Notably, they are unstable in water upon illumination as well.

\section{Electrical and Reduction}

Electrochemical (EC) immunoassay has attracted considerable attention and is one of the most promising techniques for diagnosis owing to its high sensitivity and fast response time. Besides that, nanomaterials are highly appreciated for improving EC sensitivity and intensity because of their catalytic property, conductivity, binding affinity, and large surface area. Like, AuNPs can bind biomolecules and facilitate electron transfer for catalyzing electrochemical reactions (Zhang et al., 2014). Besides, nanosheets and other hollow-structured nanomaterials can increase the loading efficiency of agents on grounds of their large surface area that enhances signal (Zhu et al., 2017).

Lopa et al. (2019) developed a AuNP modified titanium (Ti) metal substrate to detect cTnI based on DNA aptamer. AuNPs were deposited on $\mathrm{Ti}$ sheets by the potential-step deposition method. They immobilized the DNA aptamer using a selfassembled monolayer mechanism. The sensor obtained high sensitivity and specificity with the assistance of the AuNP-Ti layer and detected cTnI with the minimum detection limit of ca. 0.18 pM (Lopa et al., 2019).

Moreover, Adeel et al. (2019) modified the boron nitride nanosheets (BNNS) with AuNPs to detect MB in a low-cost, label-free and simple way (Figure 4A). BNNSs were synthesized via the hydrothermal method and were deposited on the fluorine-doped tin oxide (FTO) electrode. Subsequently, AuNPs were chemically deposited on the BNNS/FTO electrode. The AuNPs/BNNSs/FTO electrode was then used as a transducer to fix a thiol-functionalized DNA aptamer (Apt) via the Au-S covalent. When the MB bound to the sensor, $[\mathrm{Fe}(\mathrm{CN}) 6] 3-/ 4-$ was used as a redox probe to monitor the oxidation current variation. The Apt/AuNPs/BNNSs/FTO sensor showed a high signal response for $\mathrm{MB}$, with a detection limit of $34.6 \mathrm{ng} / \mathrm{mL}$.

Phonklam et al. (2020) presented a molecularly imprinted polymer-based (MIP) EC sensor using a screen-printed carbon electrode (SPCE) to detect cTnT. The MIP sensor possessed an electrodeposited polymethylene blue (PMB) redox probe on SPCE, which was functionalized with multi-walled carbon nanotubes (MWCNTs). Also, the electropolymerized polyaniline was around the cTnT immobilized platform. The sensor response was stimulated by pulse voltammetry, wherein the concentration of cTnT was negatively associated with the PMB current. The linearity range of the sensor was between $0.10-8.0 \mathrm{pg} / \mathrm{mL}$, with a detection limit of $0.040 \mathrm{pg} / \mathrm{mL}$. Similarly, Vasantham et al. (2020) integrated MWCNT with $\mathrm{Ab}_{2}$ to detect cTnI via paper-based multi-frequency impedimetric transducers. The limit of detection was $0.05 \mathrm{ng} / \mathrm{mL}$, and the response time was $\sim 1 \mathrm{~min}$.

Singh et al. (2019) developed a microfluidic biosensorintegrated mesoporous nickel vanadate hollow-nanosphere modified chitosan $\left(\mathrm{Ch}-\mathrm{Ni}_{3} \mathrm{~V}_{2} \mathrm{O}_{8}\right)$ to detect cTnI in patient samples. They synthesized chitosan-based $(\mathrm{Ch}) \mathrm{Ni}_{3} \mathrm{~V}_{2} \mathrm{O}_{8}$ hollownanospheres that could load abundant antibodies made possible by their hydroxy and amino clusters in the nanocomposite, their good adhesion capability, and their larger surface. Moreover, they amplified the electrochemical readouts because 

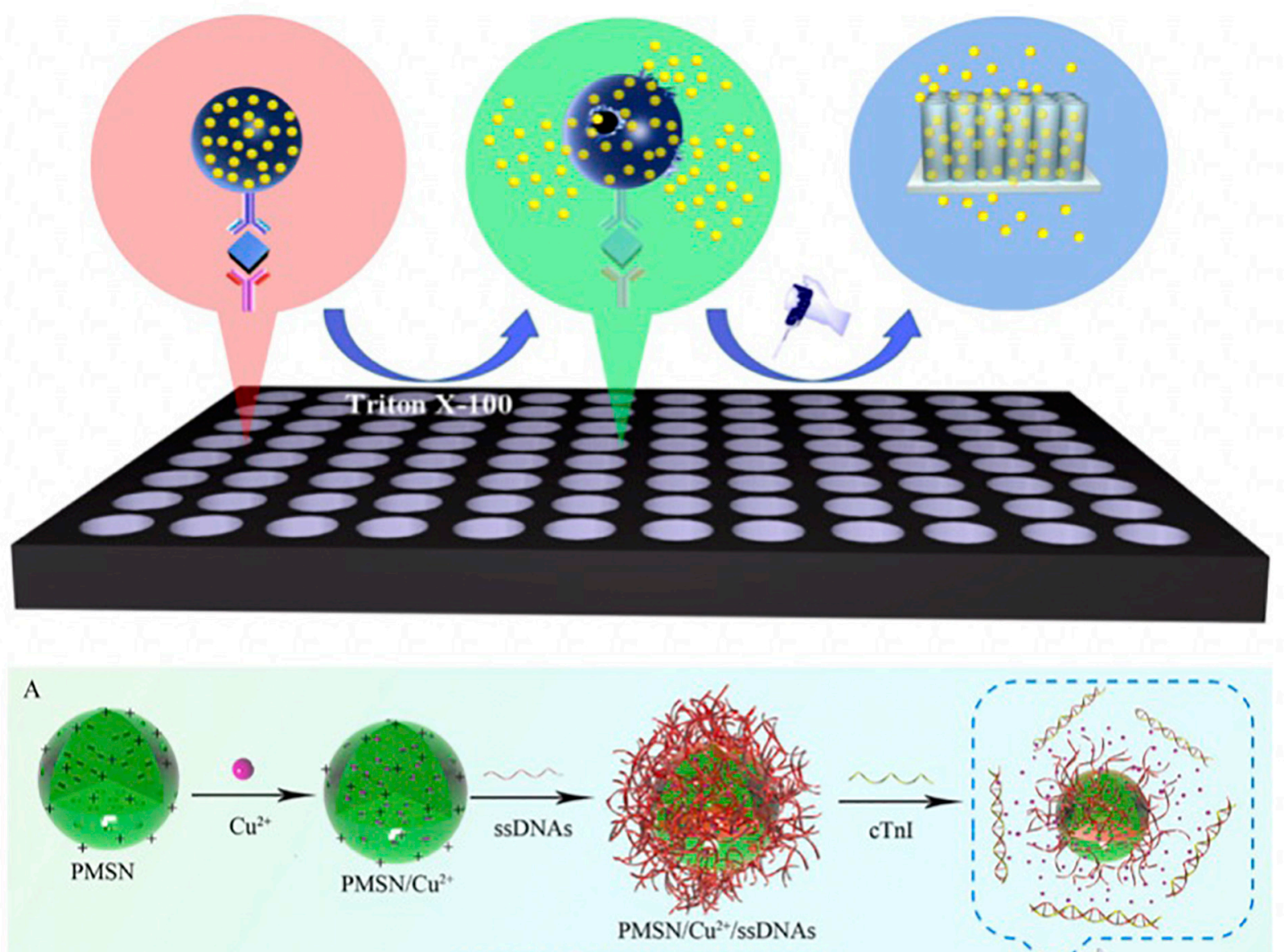

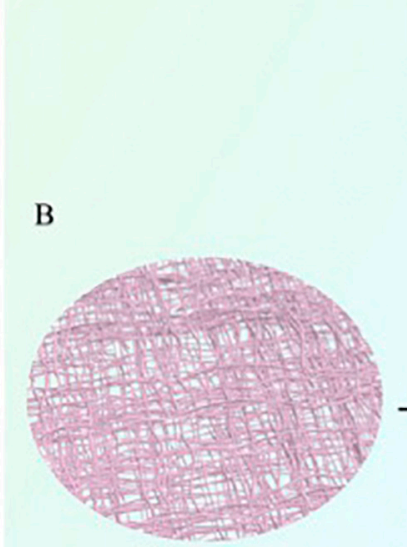

cellulose paper

$\mathrm{PMSN} / \mathrm{Cu}^{2}$

PMSN $/ \mathrm{Cu}^{2+} / \mathrm{ssDNAs}$
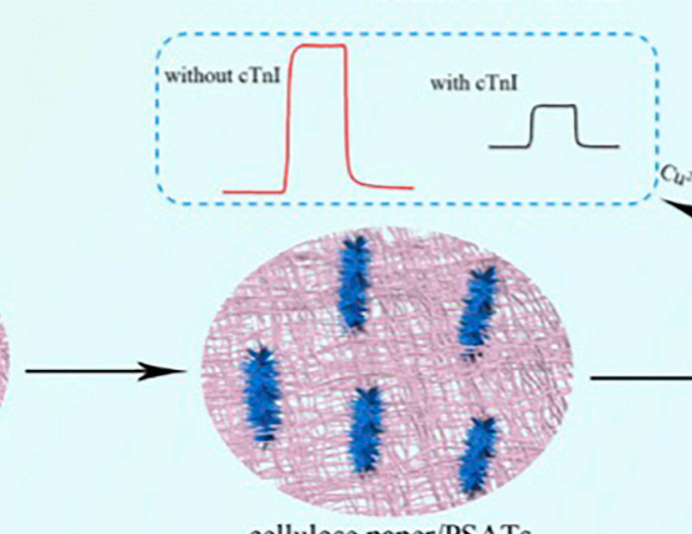

cellulose paper/PSATs

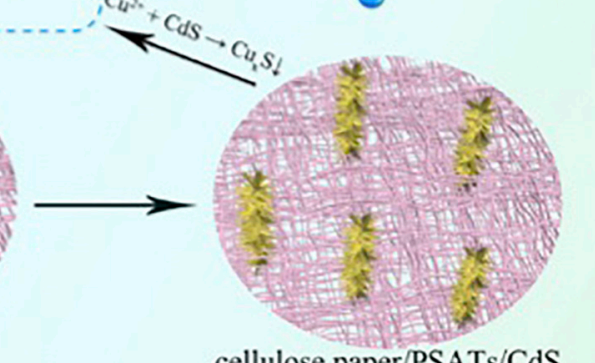

cellulose paper/PSATs/CdS

FIGURE 3 | (A) Scheme of the proposed liposomal PEC Immunoassay. Ab 1 were first loaded into 96-well plates, and then samples were incubated with Ab 1 for $1 \mathrm{~h}$. The QDLL-A $b_{2}$ was introduced after the immunorecognition of cTnl. Triton X-100 (10\%) was introduced to release the QDs that were later captured by TiO ${ }_{2}-\mathrm{NTS}$ electrode. The photocurrents were generated due to the sensitization effect (Xue et al., 2019). Copyright 2020 American Chemical Society. (B) Schematic principle of cTnl detection using PMSN/Cu2+/ssDNAs. Positive-charged PMSNs were added into $\mathrm{Cu}^{2+}$ solutions. $\mathrm{Cu}^{2+}$ entered the pores of PMSNs via diffusion. Later, ssDNAs bound cTnl specifically was added and attached on the surface of PMSNs. Once the cTnl was recognized by ssDNAs, the complexes reacted with CdS that was functionalized onto the PSATs, to form $\mathrm{Cu}_{x} \mathrm{~S}$ and diseased the photocurrent signal. The changes of photocurrent were correlated to the concentration of cTnl (Gao et al., 2019). Copyright 2020 from Elsevier B.V.

of tunable oxidation states of the $\mathrm{Ch}-\mathrm{Ni}_{3} \mathrm{~V}_{2} \mathrm{O}_{8}$ matrix. The microfluidic biosensor was fabricated using a three-electrode system, including a patterned gold $(\mathrm{Au})$, silver $(\mathrm{Ag} / \mathrm{AgCl})$, and
Ch- $\mathrm{Ni}_{3} \mathrm{~V}_{2} \mathrm{O}_{8}$ electrodes on a glass substrate. A bare Au electrode represented as the counter electrode (CE). The $\mathrm{Ch}-\mathrm{Ni}_{3} \mathrm{~V}_{2} \mathrm{O}_{8}$ composite was added on the Au-coated substrate to capture 


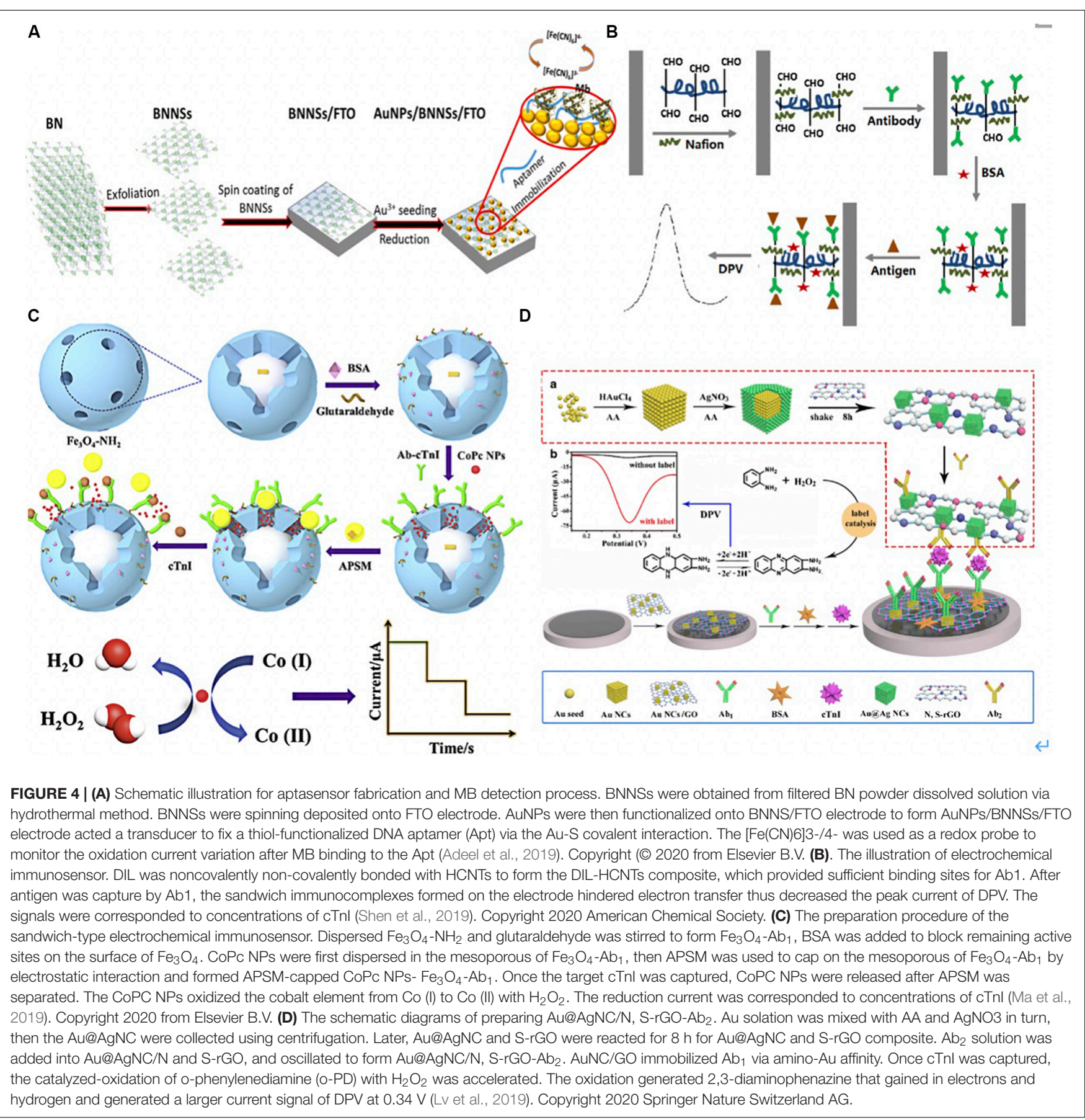

cTnI antibodies and connect the microchannels. $\mathrm{Ag} / \mathrm{AgCl}$ was deposited on the substrate using e-beam evaporation for the reference electrode (RE). This device offered $5 \mathrm{pg} / \mathrm{mL}$ limit detection of cTnI with high stability, good selectivity, and high reproducibility, and detected $\mathrm{BNP}, \mathrm{MB}$, cardiac troponin $\mathrm{C}$ (cTnC), and cTnT with specific antigens (Singh et al., 2019).

Shen et al. (2019) presented a label-free electrochemical immunosensor using a helical carbon nanotube (HCNTs)supported aldehyde-functionalized ionic liquid (DIL). The DILHCNTs provided binding sites for $A b_{1}$, which simplified the sensor construction processes (Figure 4B) (Shen et al., 2019). The sandwich immunocomplexes influenced electron transfer on the electrode, thereby decreasing the peak current of differential pulse voltammetry (DPV). The signals corresponded to concentrations of cTnI.

Additionally, Sandil et al. (2019) immobilized cTnI $\left(\mathrm{Ab}_{1}\right)$ on tungsten trioxide nanorods $\left(\mathrm{WO}_{3} \mathrm{NRs}\right)$, which were deposited on indium tin oxide (ITO) using the electrophoretic deposition technique that worked as the electrode. The authors detected cTnI in a linear detection range of $0.01-10 \mathrm{ng} / \mathrm{mL}$ 
with high reproducibility (Sandil et al., 2019). Zhang et al. (2019) synthesized $\beta$-cyclodextrins-functionalized (CDs) 3D porous graphene-supported Pd@Au nanocubes (NCs) for cTnI detection. CDs were able to increase the dispersibility of the $3 \mathrm{D}$-porous graphene and improve the capability of $\mathrm{Ab}_{2}$ capture. Besides, the electrochemical signal was improving given the Pd@Au NCs. In addition, the amino-functionalized microporous carbon sphere was functionalized using AuNPs and Th (AuNPs-FMCS-Th) to immobilize $\mathrm{Ab}_{1}$ effectively and accelerate the electron transfer process. The transfer was based on the reduction of $\mathrm{H}_{2} \mathrm{O}_{2}$ on the Th-modified electrode surface, which further amplified the signal response. The authors detected cTnI with a low detection limit of $33.3 \mathrm{fg} / \mathrm{mL}$ through the EC signal amplification labeling in the sandwich format (Zhang et al., 2019).

Similarly, $\mathrm{Ma}$ et al. (2019) utilized mesoporous $\mathrm{Fe}_{3} \mathrm{O}_{4}$ $\mathrm{NH}_{2}$ for loading cobalt phthalocyanine NPs (CoPc NPs) and captured $\mathrm{Ab}_{2}$ to form $\mathrm{Fe}_{3} \mathrm{O}_{4}-\mathrm{Ab}_{1}$ to detect cTnI. The aminated polystyrene microsphere (APSM) was used to cap on the mesoporous of $\mathrm{Fe}_{3} \mathrm{O}_{4}-\mathrm{Ab}_{1}$ by electrostatic interaction and presented as a molecular gate. Once the target cTnI was captured, CoPC NPs were released after APSM was separated. The CoPC NPs showed a superb catalytic performance that oxidized the cobalt element from Co (I) to Co (II) with the addition of $\mathrm{H}_{2} \mathrm{O}_{2}$. The reduction of current corresponded to concentrations of cTnI. This novel controlled release system-based EC immunoassay presented a broad linear range from $1.0 \mathrm{pg} / \mathrm{mL}$ to $100 \mathrm{ng} / \mathrm{mL}$ with a low detection limit of $0.39 \mathrm{pg} / \mathrm{mL}$ (Figure 4C) (Ma et al., 2019). Lv et al. (2019) functionalized the gold nanocube with graphene oxide (AuNC/GO) as the substrate to immobilize $\mathrm{Ab}_{1}$ via amino$\mathrm{Au}$ affinity. To detect cTnI, the authors utilized Au@Ag core-shell nanocubes and nitrogen/sulfur doped GO as signal amplification labels to conjugate with $\mathrm{Ab}_{2}$ via $\mathrm{Ag}-\mathrm{N}$ bonds. Once cTnI was captured, the catalyzed-oxidation of o-phenylenediamine (o-PD) with $\mathrm{H}_{2} \mathrm{O}_{2}$ was accelerated. The oxidation generated 2,3-diaminophenazine that gained in electrons and hydrogen and released an exaggerated current signal of DPV, which was used to electrochemical detect cTnI (Figure 4D) (Lv et al., 2019).

EC assay has shown advances in the sensitivity, but disadvantages remain. More specifically, the facility requires periodical calibration and care maintenance to guarantee accuracy, which is expensive and bothersome.

\section{Surface-Enhanced Raman Scattering (SERS)}

Surface-enhanced Raman scattering (SERS) immunoassay shows strong potential for CVD clinical diagnosis in view of their excellent multiplexing ability, high sensitivity, and large dynamic range (Huang et al., 2019). Typical SERS-based immunoassay uses substrates modified with $A b_{1}$ to capture targets, and the concentration of the targets is quantified by the SERS immunoprobe (Wang et al., 2017c). Nanomaterials have simplified the preparation and attachment of Raman labels thus have improved the sensitivity. For example, Fu et al. (2019) developed a capture probe/target/SERS nanotags platform to detect cTnI. They functionalized graphene oxide (GO) with AuNPs, which acted as both SERS nanotags and signal amplification carriers. The GO/AuNP complexes provided strong SERS enhancement ability and detected cTnI with a $5 \mathrm{pg} / \mathrm{mL}$ detection limit (Fu et al., 2019). Similarly, Cheng et al. (2019) loaded targets and polyclonal-antibody-conjugated Au@Ag core-shell nanoparticles in a gold-patterned chip that ran as a SERS active template for the ultrasensitive detection of cTnI and CK-MB. The limits of detection were $8.9 \mathrm{pg} / \mathrm{mL}$ and $9.7 \mathrm{pg} / \mathrm{mL}$ for cTnI and CK-MB, respectively.

While large surface area and outstanding physical properties of nanomaterials have facilitated sensitive SERS immunoassays, additional work is required on stabilizing the tag functionalization in SERS assays.

\section{Surface Plasmon Resonance (SPR)}

Surface plasmon resonance (SPR) biosensor measures the changes of the refractive index at the sensor surface. Its principle is based on charge-density oscillation that exists at the interface of two media, normally involving a metal (i.e., gold) and a dielectric. SPR has been used to detect proteins, DNA, and drugs (Mullett et al., 2000). SPR sensors are mainly classified as sensors with angular wavelength and intensity modulation (Dudak and Boyaci, 2009). Nanomaterials with plasmonic and optical properties, good distributing ability, strong photostability have amplified signals, hence, improved SPR sensitivity (Liu et al., 2013).

Recently, Chen et al. (2019) modified Au film with AuNPs and polydopamine (PDA), which ran as platforms for immobilizing $\mathrm{Ab}_{1}$ and SPR sensing. The films attracted the detection antibody on the PDA-coated $\mathrm{Fe}_{3} \mathrm{O}_{4}$ as the immune probe to detect cTnI (with a detection limit of $3.75 \mathrm{ng} / \mathrm{mL}$ ) (Chen et al., 2019). The authors also introduced secondary antibody conjugated with multi-walled carbon nanotube (MWCNTs)-PDA-AgNPs to interact with cTnI exposed on the surface of probes, thus further amplifying the SPR response signal (Figure 5A).

\section{Field Effect Transistor (FET)}

Field effect transistor-based (FET) sensors have been applied in the biomedical analysis on grounds of their small size, high versatility, and low costs (Syedmoradi et al., 2019). FET-based sensors use an electric field to control the flow of current on platforms such as silicon nanowire and graphene (Kaisti, 2017).

Silicon nanoribbon fabricated biosensors are highly sensitive and uniform. However, they are expensive and complicated, requiring oxidation, photolithography, and wet etching. In contrast, semiconducting metal-oxide-based field-effect transistors (FET) biosensors show advantages, as simplicity and reliability. Photolithography-free shadow mask fabrication methods are also beneficial compared to silicon-based sensors. To give an example, Liu et al. developed a highly uniform, sensitive, and reusable $\mathrm{In}_{2} \mathrm{O}_{3}$ nanoribbon biosensor array using a lithography-free, scalable, and facile fabrication with high time efficiency (Figure 5B) (Liu Q. et al., 2016). The nanoribbons were formed through a first-layer shadow mask that was attached to a silicon substrate using $\mathrm{In}_{2} \mathrm{O}_{3}$ sputter-coating. 

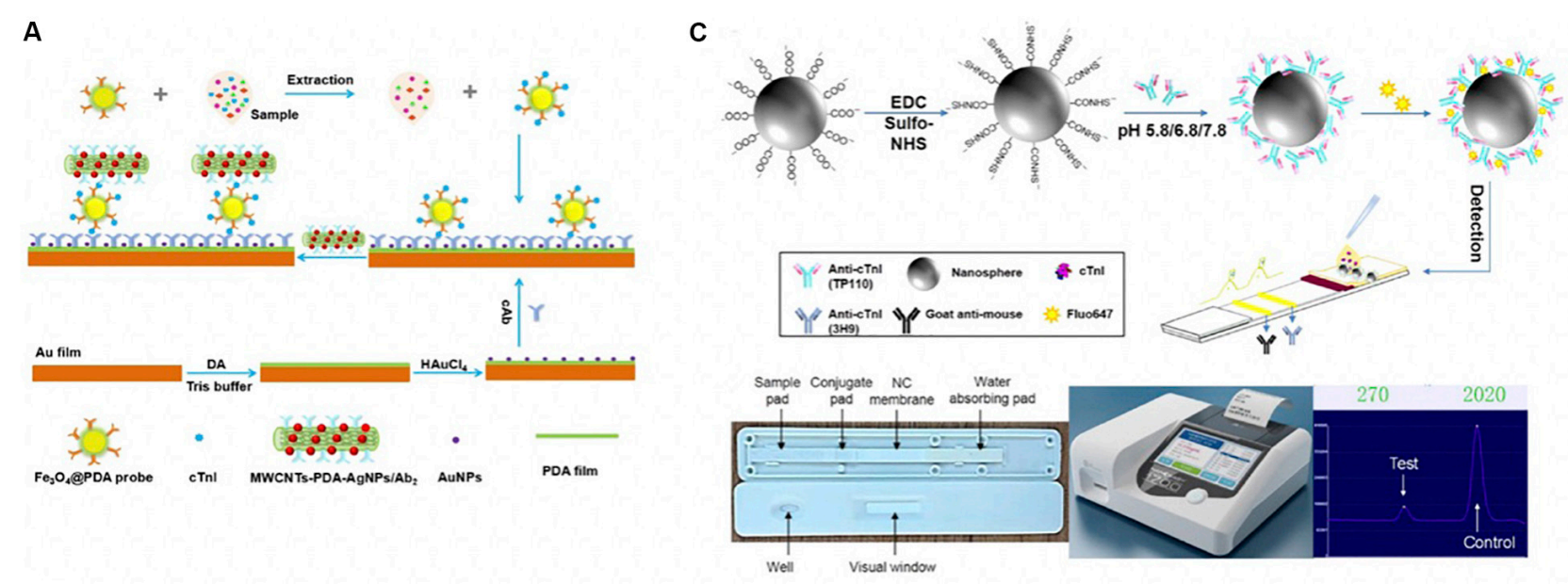

B
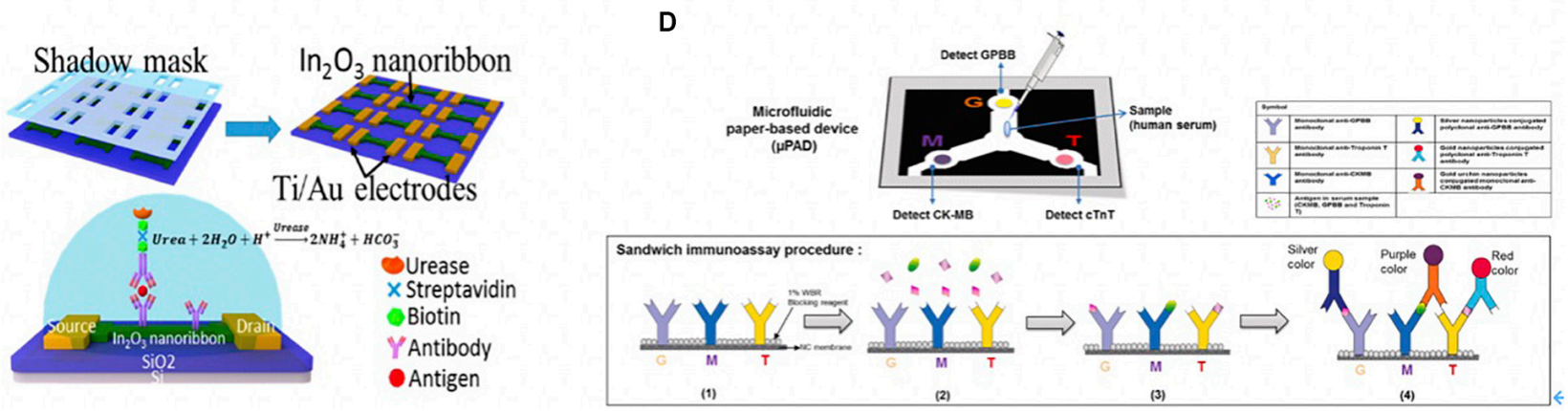

FIGURE 5 | (A) The schematic diagram of experimental procedure. A bare Au film with soaked into DA solution in Tris-buffer to form PDA-Au film. Afterward, AuNPs were deposited onto PDA-Au film with the help of $\mathrm{HAuCl}_{4}$ to improve the sensitivity. After $30 \mathrm{~min}, \mathrm{Ab}_{1}$ was immobilized on the PDA-Au for further cTnl capture. As for detection probe, $\mathrm{Fe}_{3} \mathrm{O}_{4} @ P D A-d e t e c t i o n$ antibody immune probe was collected with external magnet after $\mathrm{Fe}_{3} \mathrm{O}_{4} @ P D A$ and detection antibody were mixed and shake for $24 \mathrm{~h}$. Then samples with different concentrations of cTnl were incubated with $\mathrm{Fe}_{3} \mathrm{O}_{4} @ P D A$-detection antibody, and the nanoconjugates were collected by a magnet. Once the resonant wavelength of probes was stable, MWCNTS-PDA-AgNPs/secondary antibody was added to enhance SPR response signals (Chen et al., 2019). Copyright 2020 from Elsevier B.V. (B) Schematic of $\operatorname{In}_{2} \mathrm{O}_{3}$ nanoribbon biosensor and electronic ELISA for cardiac biomarker detection. The first shadow mask was attached onto the $\mathrm{SiO} / \mathrm{Si}$ wafer, and then $\mathrm{In}_{2} \mathrm{O}_{3}$ ribbons were deposited using radio frequency (RF). Nanoribbons were obtained after removing first-layer shadow mask. A second shadow mask was attached to define the Ti/Au disposition, which used e-beam evaporation. Finally, a FET-based sensor was completed after removing shadow mask. Captured antibodies were fixed on the $\mathrm{In}_{2} \mathrm{O}_{3}$ surface and captured the biomarkers. Biomarkers were fixed between the capture antibody and a biotinylated secondary antibody that is specific to biomarkers. The biotin tales of the secondary antibody was to capture streptavidin, which bound to a biotinylated urease that led to deprotonation the hydroxyl groups on the nanoribbon and increased the negative surface charges. The change of surface charge was detected by FET sensor because negative charges decreased the conduction of nanoribbons (Liu Q. et al., 2016). Copyright 2020 American Chemical Society. (C) Schematic representation of the preparation of antibody-modified nanoprobes involved in the lateral flow immunoassay. Carboxylated Nanospheres (CNs) were incubated with $N$-(3-dimethylaminopropyl)- $N$ '-ethylcarbodiimide hydrochloride crystalline (EDC) and $N$-hydroxysulfosuccinimide sodium salt (sulfo-NHS), the mixtures were collected centrifugation. TP110 (detection antibody) was incubated with CNs at 5.8, 6.8, or 7.8 pH. Florescent molecules were conjugated with CNs-TP110 for later detection on LFA. Briefly, sample flowed through sample pad, and conjugated with fluorescent labeled CNs-TP110 on the conjugate pad. The complexes went through NC membrane that immobilized $\mathrm{Ab} 1(3 \mathrm{H} 9)$ on the test line and Goat anti-mouse on the control line for further antigen capture. The strip was read by a fluorescent analyzer after 15 min (Lou et al., 2019b). Copyright 2020 American Chemical Society. (D) Scheme of fabrication of the microfluidic paper-based device $(\mu \mathrm{PAD})$ for multiplex detection of cardiac markers. Capture antibodies were immobilized onto NC membrane at three positions (G for GPBB, M for CK-MB, and T for troponin T). Serum sample was added at central sample zone. After antibody-antigen capture, AuNPs conjugated anti-cTnT (red), silver-nanoparticles (AgNPs) conjugated anti-GPBB (yellow) and Gold urchin nanoparticles conjugated anti-CKMB (purple) were added for color detection (Lim et al., 2019). Copyright 2020 from Elsevier B.V.

The nanoribbons went through a metal electrode deposition process that was defined by a second-layer shadow mask. Two shadow masks were simply removed instead of being lifted off, as in the case in photolithography. Captured antibodies were fixed on the $\operatorname{In}_{2} \mathrm{O}_{3}$ surface using $\mathrm{N}$-(3-dimethylaminopropyl)$N$ '-ethylcarbodiimide hydrochloride/ $N$-hydroxysuccinimide (EDC/NHS) chemistry. A biotinylated secondary antibody was introduced to attach biomarkers, and its biotin tales were bounded to the streptavidin that attracted biotinylated urease later. Urea increased the $\mathrm{pH}$ of the solution, hence, causing the deprotonation of hydroxyl groups on the nanoribbon and lowering surface potential. Consequently, the conduction of the n-type nanoribbon FETs was decreased due to increased negative surface charges. They detected cTnI, CK-MB, and BNP down to $1 \mathrm{pg} / \mathrm{mL}, 0.1 \mathrm{ng} / \mathrm{mL}$, and $10 \mathrm{pg} / \mathrm{mL}$ concentration range, respectively. 


\section{Enzyme-Linked Immunosorbent Assay (ELISA)}

Enzyme-Linked Immunosorbent Assay (ELISA) is a commercialized method that identifies the concentration of targets through the color change of antigen-antibody reactions using an enzyme-linked conjugate and enzyme substrate. Even though ELISA shows advantages in reading results, it still requires more effort to improve sensitivity and accuracy (Aydin, 2015). Unique physical properties and biocompatibility of nanomaterials have greatly improved the performance of ELISA and below lateral flow assay (LFA). Nanofibers have the potential to reduce non-specific binding and improve binding efficiency due to their large surface area as an illustration. In addition, AuNPs conjugated with functional materials, such as HRP could amplify the detection signal in the assay (Wang W. et al., 2018).

Recently, Jiao et al. (2019) completed a multimodal ELISA diagnosis based on photothermal effect and the peroxidasemimicking property in Au@Pt nanodendrites. The cTnI target was quantified using photothermal, colorimetric, and ratiometric fluorescent signals simultaneously.

\section{Paper Based Lateral Flow Assay (LFA)}

Lateral flow assay detects targets in a fast, simple, and cheap manner that has attracted much interests in recent years (Koczula and Gallotta, 2016). Lou et al. (2019a) functionalized the LFA with a multi-layer structure, including the BSA layer to increase biotinylation sites, a streptavidin layer loaded with a fluorescent dye, and an outermost layer on which the biotinylated antibody is bounded to the streptavidin. Due to the high loading efficiency of fluorescent molecules, the authors detected the cTnI within the range of $0.049-50 \mathrm{ng} / \mathrm{mL}$ (Lou et al., 2019a). Recently, Lou et al. (2019b) conjugated $\mathrm{Ab}_{2}$ onto polystyrene nanospheres at $\mathrm{pH} 5.8$ for fast and sensitive immunodetection. At $\mathrm{pH} 5.8$, the tail-on orientated antibodies (TP110) were conjugated on the carboxylated nanospheres (CNs) because of the charge distribution and the hydrophobic area of antibodies. As a result, the loading capacity of TP110 was increased, thus the authors detected cTnI with high sensitivity. The detailed procedure was illustrated in Figure 5C. Lim et al. (2019) utilized AuNPs conjugated anti-cTnT, silvernanoparticles (AgNPs) conjugated anti-GPBB, and Gold urchin nanoparticles conjugated anti-CKMB as probes to detect multiplexed biomarkers simultaneously. The serum sample was loaded on the central sample pad and flowed through the NC membrane where anti-GPBB, anti-CK-MB, and anti-cTnT were immobilized on at three positions. Nanoparticles-conjugated detection antibodies were added on the NC membrane for color detection in the end. The detailed illustration was in Figure 5D (Lim et al., 2019).

Despite the convenience of ELISA and LFA in analyzing biomolecules, they have some drawbacks. ELISA suffers from complicated procedures, long assay duration (at least 2-3 h), and large sample consumptions. LFA requires labor-intensive preparations and is highly susceptible to false positives/negatives due to improper operations.

\section{NANOTECHNOLOGY-BASED MOI}

Nanomaterials with good bioavailability and versatility have increased the accuracy and specificity of clinical MOI applications thanks to improved resolution, signal amplification, and simple manipulation. Among other nanomaterials, nanoparticles are suitable for MOI since their mobilities in both internal and external vascular systems, high surface area to volume ratio, and imaging functionality. These advantages allow them to circulate through human bodies with low restrictions and produce functional imaging vehicles as contrast agents when they are applied in MOI settings, which leads to significantly improved diagnosis efficiency.

Nanoparticles can be used for RNA detection in intravascular systems because of their mobility. Injected or swallowed nanoparticles that are functionalized with MOI detectable molecules can circulate through the human body and target specific RNA for diagnosis. However, the size, shape, morphology, and density of functionalized nanoparticles should be explored carefully since the RNA detection requires nanoparticles entering and interacting with cells.

In addition, nanoparticles can work as nanoscale contrast agents by incorporating materials such as photoacoustic, fluorescent, radioactive, paramagnetic, superparamagnetic, electron-dense, light-scattering particles, and multimodal functional groups that are detectable by MOI.

The fluorescent material is a popular choice to conjugate with nanoparticles. For example, fluorescence labeled quantum dots (QDs) exhibit good performance in atherosclerotic plagues imaging (Jaffer et al., 2007). Popular radionuclides, including ${ }^{18} \mathrm{~F}$, ${ }^{64} \mathrm{Cu},{ }^{68} \mathrm{Ga},{ }^{124} \mathrm{I},{ }^{86} \mathrm{Y}$, have been conjugated with QDs, UCNPs, AuNPs, and NCs and have demonstrated good diagnostic functions (Saraste et al., 2009). For instance, radiolabeled nanoparticles play significant roles for atherosclerotic plagues under PET (Dobrucki and Sinusas, 2010). Radionuclides can be labeled either on the surface or encapsulated inside nanoparticles.

Additionally, superparamagnetic nanoparticles, like iron oxide (IO) nanoparticles and predominately magnetite $\left(\mathrm{Fe}_{2} \mathrm{O}_{3} / \mathrm{Fe}_{3} \mathrm{O}_{4}\right)$, can improve the sensitivity of MRI by providing dark contrast to enhance the signal. For instance, MRI can detect thrombus (Chen and $\mathrm{Wu}, 2011$ ), and the composition of plaques, including the fibrous cap and necrotic core, macrophage content, plaque neovascularization, intraplaque hemorrhage, and mural thrombus using superparamagnetic nanoparticles as contrasts (Avelar et al., 2017).

Also, AuNPs with good optical properties are good signal enhancers for photoacoustic tomography (PAT) (Taruttis et al., 2010). For example, Pan et al. (2014) successfully detected thrombus using gold nanobeacons under PAT. AuNPs can enhance the signal of coherence tomography (OCT) based on light-scattering as well.

Moreover, AuNPs were also widely used in CT as contrast agents. Hyafil et al. (2007) identified macrophages in atherosclerotic plagues using iodinated AuNPs facilitated CT. Kim et al. (2012) used polyethylene glycol (PEG)-coated AuNPs to improve the performance of CT scanning. They utilized PEG-coated GNPs as a contrast agent, in which the PEG-coating 
prevented antibiofouling and extended lifetime of AuNPs in the bloodstream. The PEG-coated GNPs obtained a better X-ray absorption coefficient and thus provided high-resolution images.

\section{CONCLUSION AND FUTURE PERSPECTIVE}

Current clinical challenges of CVDs include generating straightforward, accurate diagnostic clinical decisions, and monitoring drug responses frequently. To overcome these difficulties, various platforms have been proposed. Among these platforms, CIAs have gained attraction since they can measure and evaluate the expression of biomarkers for the prediction and diagnosis of disease in a sensitive, rapid, cheap, and noninvasive manner. Additionally, MOI settings have emerged as promising techniques for CVD diagnosis thanks to their excellent imaging capabilities that facilitate physicians to make decisions. Even though significant advances in CIAs and MOI have been made regarding CVD diagnosis, the early-stage diagnosis is still challenging since symptoms of early-stage CVDs are vague, and the expression level of cardiac biomarkers at early-stage is relatively low for detection.

Therefore, novel platforms with improved sensitivity and specificity are required. As summarized in this review, nanotechnology has greatly contributed to the developments of MOI and CIA on account of its specific physicochemical properties. By virtue of their excellent biocompatibility, nanomaterials can conjugate with various biomolecules because their excellent biocompatibility. These functional biomolecules were able to increase the sensitivity and specificity of diagnostic platforms. For example, AuNP-conjugated capture antibody can reduce non-specific bindings, thereby increasing the capture specificity and eliminating background noises in various CIAs. Besides, fluorescence lumiphore conjugated nanomaterials can work as enhancers to amplify the detective signals in ELISA, or as contrast agents in MOI. In addition, except for functionalized with other biomolecules, nanomaterial itself can serve as a signal enhancer. This is made possible by their unique optical, electrical and plasmonic properties, silica NPs can quench photocurrent effectively in PEC biosensors as an example. Moreover, nanomaterials with a large surface area (e.g., nanocubes) can improve the loading efficiency of biomolecules to increase the sensitivity of CIAs. To better elucidate CIAs in CVD diagnosis, the lasted outcomes of nanotechnology assisted CIAs (e.g., ECL) was introduced, with comparison to the sensitivity and detection range of cardiac targets among these

\section{REFERENCES}

Abdorahim, M., Rabiee, M., Alhosseini, S. N., Tahriri, M., Yazdanpanah, S., Alavi, S. H., et al. (2016). Nanomaterials-based electrochemical immunosensors for cardiac troponin recognition: an illustrated review. TrAC Trends Anal. Chem. 82, 337-347. doi: 10.1016/j.trac.2016.06.015

Adeel, M., Rahman, M. M., and Lee, J. J. (2019). Label-free aptasensor for the detection of cardiac biomarker myoglobin based on gold nanoparticles assays. We also reviewed the clinical applications of nanoparticles in MOI settings. In this regard, we believe strongly bridging clinical platforms and nanotechnology is necessary for directing future research plans.

In this review, we have highlighted the advantages of CIAs. They are non-invasive, cheap, sensitivity, and convenient. Its repeat-sampling ability also makes it ideal for long-term diagnosis and prognosis. However, the CIA testing still faces challenges. An important concern is the sensitivity and specificity of the biomarker. Previous researchers have shown that a single marker may be insufficient, lack sensitivity and specificity for accurate CVD diagnosis. It is unrealistic to provide clear diagnosis results using only one biomarker owing to the complexity, heterogeneity and diversity of pathogenesis in different populations. Additionally, biomarkers may be regulated differently during the development of pathologies. Consequently, even though we can diagnosis some clinical subjects who have high risks for certain diseases using biomarkers (e.g., cTnI for AMI), we have insufficient information on the progression and states of the diseases (Madhurantakam et al., 2018). To solve this problem, multiplexed biomarker panels are critical. The multiplexed analysis of various biomarkers can establish correlations (or scores) with high specificities and predictive values, as a result, can improve the accuracy of diagnostic decisions. Hence, the fabrication of CIAs should focus on multiplexed analysis in the future. In addition, current findings on biomarkers are based on relatively small samples, which may possess large variations (Sayed et al., 2014). Most of the studies only focused on the correlation between biomarker expression level and single disease. The pathological significance behind the biomarker expression level changing is not addressed yet. As such, large-scale and systematic clinical studies are needed to recognize and better understand the mechanisms of biomarkers. Most importantly, combination with advanced analytic tools (e.g., machine learning) that is capable of developing objective and automatic algorithms to analyze large-scale and highdimensional-multiplexed data should be highlighted in future studies, which are supposed to greatly improve the efficiency and accuracy of diagnosis.

\section{AUTHOR CONTRIBUTIONS}

$\mathrm{ZY}$ and JZ coordinated this project. CS and HX wrote this manuscript. CS and HX collected and summarized the literatures. YM edited the figures in this manuscript and revised this manuscript. decorated boron nitride nanosheets. Biosens. Bioelectron. 126, 143-150. doi: 10.1016/j.bios.2018.10.060

Adhikari, J., Keasberry, N. A., Mahadi, A. H., Yoshikawa, H., Tamiya, E., and Ahmed, M. U. (2019). An ultra-sensitive label-free electrochemiluminescence CKMB immunosensor using a novel nanocomposite-modified printed electrode. RSC Adv. 9, 34283-34292. doi: 10.1039/c9ra05016g

Ali, M., Sajid, M., Khalid, M. A. U., Kim, S. W., Lim, J. H., Huh, D., et al. (2020). A fluorescent lateral flow biosensor for the quantitative detection of Vaspin using 
upconverting nanoparticles. Spectrochim. Acta Part A Mol. Biomol. Spectrosc. 226:117610. doi: 10.1016/j.saa.2019.117610

Anderon, L. (2005). Candidate-based proteomics in the search for biomarkers of cardiovascular disease. J. Physiol. 563(Pt 1), 23-60. doi: 10.1113/jphysiol.2004. 080473

Anderson, T. J., Grégoire, J., Hegele, R. A., Couture, P., Mancini, G. B. J., McPherson, R., et al. (2013). 2012 update of the canadian cardiovascular society guidelines for the diagnosis and treatment of dyslipidemia for the prevention of cardiovascular disease in the adult. Can. J. Cardiol. 29, 151-167. doi: 10.1016/j. cjca.2012.11.032

Apple, F. S., Falahati, A., Paulsen, P. R., Miller, E. A., and Sharkey, S. W. (1997). Improved detection of minor ischemic myocardial injury with measurement of serum cardiac troponin I. Clin. Chem. 43, 2047-2051. doi: 10.1093/clinchem/ 43.11.2047

Article, E. (2018). CT SCAN. Diagn. Radiol. Radiother. 1, 162-169. doi: 10.22328/ 2079-5343-2018-9-1-162-169

Avelar, E., Strickland, C. R., and Rosito, G. (2017). Role of imaging in cardiooncology. Curr. Treat. Options Cardiovasc. Med. 19:46. doi: 10.1007/s11936017-0546-2

Aydin, S. (2015). A short history, principles, and types of ELISA, and our laboratory experience with peptide/protein analyses using ELISA. Peptides 72, 4-15. doi: 10.1016/j.peptides.2015.04.012

Bang, C., Batkai, S., Dangwal, S., Gupta, S. K., Foinquinos, A., Holzmann, A., et al. (2014). Cardiac fibroblast-derived microRNA passenger strand-enriched exosomes mediate cardiomyocyte hypertrophy. J. Clin. Invest. 124, 2136-2146. doi: 10.1172/JCI70577

Chakrabarti, S., Wu, X., Yang, Z., Wu, L., Yong, S. L., Zhang, C., et al. (2013). MOG1 rescues defective trafficking of nav1.5 mutations in brugada syndrome and sick sinus syndrome. Circ. Arrhythmia Electrophysiol. 6, 392-401. doi: 10.1161/CIRCEP.111.000206

Chen, F., Wu, Q., Song, D., Wang, X., Ma, P., and Sun, Y. (2019). Fe 3 O 4 @PDA immune probe-based signal amplification in surface plasmon resonance (SPR) biosensing of human cardiac troponin I. Colloids Surf. B Biointerfaces. 177, 105-111. doi: 10.1016/j.colsurfb.2019.01.053

Chen, I. Y., and Wu, J. C. (2011). Cardiovascular molecular imaging: focus on clinical translation. Circulation 123, 425-443. doi: 10.1161/ CIRCULATIONAHA.109.916338

Chen, Y., Song, Y., Huang, J., Qu, M., Zhang, Y., Geng, J., et al. (2017). Increased circulating exosomal miRNA-223 is associated with acute ischemic stroke. Front. Neurol. 8:57. doi: 10.3389/fneur.2017.00057

Chen, Z., Zhang, A., Wang, X., Zhu, J., Fan, Y., Yu, H., et al. (2017). The advances of carbon nanotubes in cancer diagnostics and therapeutics. J. Nanomater. 2017:3418932. doi: 10.1155/2017/3418932

Cheng, Y., Wang, X., Yang, J., Duan, X., Yao, Y., Shi, X., et al. (2012). A translational study of urine miRNAs in acute myocardial infarction. J. Mol. Cell. Cardiol. 53, 668-676. doi: 10.1016/j.yjmcc.2012.08.010

Cheng, Z., Wang, R., Xing, Y., Zhao, L., Choo, J., and Yu, F. (2019). SERS-based immunoassay using gold-patterned array chips for rapid and sensitive detection of dual cardiac biomarkers. Analyst 144, 6533-6540. doi: 10.1039/c9an01260e

Christenson, E., and Christenson, R. H. (2013). The role of cardiac biomarkers in the diagnosis and management of patients presenting with suspected acute coronary syndrome. Ann. Lab. Med. 33, 309-318. doi: 10.3343/alm.2013.33.5. 309

Corsten, M. F., Dennert, R., Jochems, S., Kuznetsova, T., Devaux, Y., Hofstra, L., et al. (2010). Circulating MicroRNA-208b and MicroRNA-499 reflect myocardial damage in cardiovascular disease. Circ. Cardiovasc. Genet. 3, 499506. doi: 10.1161/CIRCGENETICS.110.957415

D’Agostino, R. B., Vasan, R. S., Pencina, M. J., Wolf, P. A., Cobain, M., Massaro, J. M., et al. (2008). General cardiovascular risk profile for use in primary care: the Framingham heart study. Circulation. 117, 743-753. doi: 10.1161/ CIRCULATIONAHA.107.699579

de Jong, O. G., Verhaar, M. C., Chen, Y., Vader, P., Gremmels, H., Posthuma, G., et al. (2012). Cellular stress conditions are reflected in the protein and RNA content of endothelial cell-derived exosomes. J. Extracell. Vesicles 1:18396. doi: $10.3402 /$ jev.vli0.18396

Devaux, Y., Vausort, M., McCann, G. P., Kelly, D., Collignon, O., Ng, L. L., et al. (2013). A panel of 4 microRNAs Facilitates the prediction of left ventricular contractility after acute myocardial infarction. PLoS One 8:e70644. doi: 10.1371/ journal.pone. 0070644

Dobrucki, L. W., and Sinusas, A. J. (2010). PET and SPECT in cardiovascular molecular imaging. Nat. Rev. Cardiol. 7, 38-47. doi: 10.1038/nrcardio.2009.201

Dong, W., Mo, X., Wang, Y., Lei, Q., and Li, H. (2020). Photoelectrochemical immunosensor based on ZnIn2S4/Bi2Se3 nanocomposite for the determination of cardiac troponin I. Anal. Lett. doi: 10.1080/00032719.2020.1721003

Dong, X., Zhao, G., Li, X., Miao, J. C., Fang, J., Wei, Q., et al. (2019). Electrochemiluminescence immunoassay for the $\mathrm{N}$-terminal pro-B-type natriuretic peptide based on resonance energy transfer between a self-enhanced luminophore composed of silver nanocubes on gold nanoparticles and a metalorganic framework of type MIL-125. Microchim. Acta 186:811. doi: 10.1007/ s00604-019-3969-5

Dudak, F. C., and Boyaci, I. H. (2009). Rapid and label-free bacteria detection by surface plasmon resonance (SPR) biosensors. Biotechnol. J. 4, 1003-1011. doi: 10.1002/biot.200800316

Durrani-Kolarik, S., Pool, C. A., Gray, A., Heyob, K. M., Cismowski, M. J., Pryhuber, G., et al. (2017). miR-29b supplementation decreases expression of matrix proteins and improves alveolarization in mice exposed to maternal inflammation and neonatal hyperoxia. Am. J. Physiol. Lung Cell. Mol. Physiol. 313, L339-L349. doi: 10.1152/ajplung.00273.2016

Ellis, K. L., Cameron, V. A., Troughton, R. W., Frampton, C. M., Ellmers, L. J., and Richards, A. M. (2013). Circulating microRNAs as candidate markers to distinguish heart failure in breathless patients. Eur. J. Heart Fail. 15, 1138-1147. doi: 10.1093/eurjhf/hft078

Fan, C., Tang, Y., Zhao, M., Lou, X., Pretorius, D., Menasche, P., et al. (2020a). CHIR99021 and fibroblast growth factor 1 enhance the regenerative potency of human cardiac muscle patch after myocardial infarction in mice. J. Mol. Cell. Cardiol. 141, 1-10. doi: 10.1016/j.yjmcc.2020.03.003

Fan, C., Zhang, E., Joshi, J., Yang, J., Zhang, J., and Zhu, W. (2020b). Utilization of human induced pluripotent stem cells for cardiac repair. Front. Cell Dev. Biol. 8:36. doi: $10.3389 /$ fcell. 2020.00036

Feng, Q. M., Shen, Y. Z., Li, M. X., Zhang, Z. L., Zhao, W., Xu, J. J., et al. (2016). Dual-wavelength electrochemiluminescence ratiometry based on resonance energy transfer between au nanoparticles functionalized g-C3N4 Nanosheet and $\mathrm{Ru}(\mathrm{bpy}) 32+$ for microRNA Detection. Anal. Chem. 88, 937-944. doi: 10. 1021/acs.analchem.5b03670

Fesmire, F. M., Percy, R. F., Bardoner, J. B., Wharton, D. R., and Calhoun, F. B. (1998). Usefulness of automated serial 12-lead ECG monitoring during the initial emergency department evaluation of patients with chest pain. Ann. Emerg. Med. 31, 3-11. doi: 10.1016/S0196-0644(98)70274-4

Friese, R. S., Altshuler, A. E., Zhang, K., Miramontes-Gonzalez, J. P., Hightower, C. M., Jirout, M. L., et al. (2013). MicroRNA-22 and promoter motif polymorphisms at the Chga locus in genetic hypertension: functional andtherapeutic implications forgeneexpressionand the pathogenesis of hypertension. Hum. Mol. Genet. 22, 3624-3640. doi: 10.1093/hmg/ddt213

Fu, X., Wang, Y., Liu, Y., Liu, H., Fu, L., Wen, J., et al. (2019). A graphene oxide/gold nanoparticle-based amplification method for SERS immunoassay of cardiac troponin I. Analyst 144, 1582-1589. doi: 10.1039/c8an02022a

Gan, C. S., Wang, C. W., and Tan, K. S. (2012). Circulatory microRNA-145 expression is increased in cerebral ischemia. Genet. Mol. Res. 11, 147-152. doi: 10.4238/2012.January.27.1

Gao, C., Xue, J., Zhang, L., Zhao, P., Cui, K., Ge, S., et al. (2019). Paper based modification-free photoelectrochemical sensing platform with singlecrystalline aloe like $\mathrm{TiO} 2$ as electron transporting material for $\mathrm{cTnI}$ detection. Biosens. Bioelectron. 131, 17-23. doi: 10.1016/j.bios.2019.01.038

Gidlöf, O., Andersson, P., Van Der Pals, J., Götberg, M., and Erlinge, D. (2011). Cardiospecific microRNA plasma levels correlate with troponin and cardiac function in patients with ST elevation myocardial infarction, are selectively dependent on renal elimination, and can be detected in urine samples. Cardiology. 118, 217-226. doi: 10.1159/000328869

Golberg, D., Bando, Y., Huang, Y., Terao, T., Mitome, M., Tang, C., et al. (2010). Boron nitride nanotubes and nanosheets. ACS Nano 4, 2979-2993. doi: 10.1021/ nn1006495

Goren, Y., Kushnir, M., Zafrir, B., Tabak, S., Lewis, B. S., and Amir, O. (2012). Serum levels of microRNAs in patients with heart failure. Eur. J. Heart Fail. 14, 147-154. doi: 10.1093/eurjhf/hfr155 
Govindappa, P. K., Patil, M., Garikipati, V. N. S., Verma, S. K., Saheera, S., Narasimhan, G., et al. (2020). Targeting exosome-associated human antigen R attenuates fibrosis and inflammation in diabetic heart. FASEB J. 34, 2238-2251. doi: 10.1096/fj.201901995R

Guo, X., Zong, L., Jiao, Y., Han, Y., Zhang, X., Xu, J., et al. (2019). Signal-enhanced detection of multiplexed cardiac biomarkers by a paper-based fluorogenic immunodevice integrated with zinc oxide nanowires. Anal. Chem. 91, 93009307. doi: 10.1021/acs.analchem.9b02557

Haase, M., and Schäfer, H. (2011). Upconverting nanoparticles. Angew. Chem. Int. Ed Engl. 50, 5808-5829. doi: 10.1002/anie.201005159

Han, G. R., and Kim, M. G. (2019). Design, synthesis, and evaluation of gold nanoparticle-antibody-horseradish peroxidase conjugates for highly sensitive chemiluminescence immunoassay (hs-CLIA). Biotechnol. Bioprocess. Eng. 24, 206-214. doi: 10.1007/s12257-018-0369-3

Hao, N., Li, X. L., Zhang, H. R., Xu, J. J., and Chen, H. Y. (2014). A highly sensitive ratiometric electrochemiluminescent biosensor for microRNA detection based on cyclic enzyme amplification and resonance energy transfer. Chem. Commun. 50, 14828-14830. doi: 10.1039/c4cc06801g

Hashemi, R. H., Bradley, W. G., and Lisanti, C. J. (2012). MRI: The Basics. Philadelphia, PA: Lippincott Williams \& Wilkins.

Ho, K. J. (2018). "Cardiovascular diseases," in Nutritional Aspects of Aging, Vol. 2, ed. L. H. Chen (Boca Raton, FL: CRC Press), doi: 10.1201/9781351075145

Homola, J., Yee, S. S., and Gauglitz, G. (1999). Surface plasmon resonance sensors: review. Sens. Actuat. B Chem. 54, 3-15. doi: 10.1016/S0925-4005(98)00321-9

Huang, Z., Zhang, A., Zhang, Q., and Cui, D. (2019). Nanomaterial-based SERS sensing technology for biomedical application. J. Mater. Chem. B 7, 3755-3774. doi: $10.1039 /$ c9tb00666d

Hur, J., Kim, Y. J., Lee, H. J., Nam, J. E., Ha, J. W., Heo, J. H., et al. (2011). Dual-enhanced cardiac CT for detection of left atrial appendage thrombus in patients with stroke?: a prospective comparison study with transesophageal echocardiography. Stroke 42, 2471-2477. doi: 10.1161/STROKEAHA.110. 611293

Hur, J., Kim, Y. J., Lee, H. J., Nam, J. E., Hong, J., Kim, H. Y., et al. (2012). Cardioembolic stroke: dual-energy cardiac CT for differentiation of left atrial appendage thrombus and circulatory stasis. Radiology 263, 688-695. doi: 10. $1148 /$ radiol.12111691

Hutton, B. F. (2014). The origins of SPECT and SPECT/CT. Eur. J. Nucl. Med. Mol. Imaging. 41(Suppl. 1), S3-S16. doi: 10.1007/s00259-013-2606-5

Hyafil, F., Cornily, J. C., Feig, J. E., Gordon, R., Vucic, E., Amirbekian, V., et al. (2007). Noninvasive detection of macrophages using a nanoparticulate contrast agent for computed tomography. Nat. Med. 13, 636-641. doi: 10.1038/nm1571

Jaffer, F. A., Libby, P., and Weissleder, R. (2007). Molecular imaging of cardiovascular disease. Circulation 116, 1052-1061. doi: 10.1161/ CIRCULATIONAHA.106.647164

Ji, T., Xu, X., Wang, X., Zhou, Q., Ding, W., Chen, B., et al. (2019). Point of care upconversion nanoparticles-based lateral flow assay quantifying myoglobin in clinical human blood samples. Sens. Actuat. B Chem. 281, 309-316. doi: 10. 1016/j.snb.2018.11.074

Ji, X., Takahashi, R., Hiura, Y., Hirokawa, G., Fukushima, Y., and Iwai, N. (2009). Plasma miR-208 as a biomarker of myocardial injury. Clin. Chem. 55, 19441949. doi: 10.1373/clinchem.2009.125310

Jiao, L., Zhang, L., Du, W., Li, H., Yang, D., and Zhu, C. (2019). Au@Pt nanodendrites enhanced multimodal enzyme-linked immunosorbent assay. Nanoscale 11, 8798-8802. doi: 10.1039/c8nr08741e

Jo, H., Gu, H., Jeon, W., Youn, H., Her, J., Kim, S. K., et al. (2015). Electrochemical aptasensor of cardiac Troponin I for the early diagnosis of acute myocardial infarction. Anal. Chem. 87, 9869-9875. doi: 10.1021/acs.analchem.5b02312

Johnson, S. (2012). "Nanotechnology," in Encyclopedia of Applied Ethics, ed. R. Chadwick (San Diego, CA: Academic Press).

Joshi, J., Rubart, M., and Zhu, W. (2020). Optogenetics: background, methodological advances and potential applications for cardiovascular research and medicine. Front. Bioeng. Biotechnol. 7:466. doi: 10.3389/fbioe.2019.00466

Kaisti, M. (2017). Detection principles of biological and chemical FET sensors. Biosens. Bioelectron. 98, 437-448. doi: 10.1016/j.bios.2017.07.010

Kim, S. H., Kim, E. M., Lee, C. M., Kim, D. W., Lim, S. T., Sohn, M. H., et al. (2012). Synthesis of PEG-iodine-capped gold nanoparticles and their contrast enhancement in in vitro and in vivo for X-ray/CT. J. Nanomater. 2012:504026. doi: $10.1155 / 2012 / 504026$
Kirkpatrick, I. D. C., Kroeker, M. A., and Greenberg, H. M. (2003). Biphasic CT with mesenteric CT angiography in the evaluation of acute mesenteric ischemia: initial experience. Radiology 229, 91-98. doi: 10.1148/radiol.2291020991

Koczula, K. M., and Gallotta, A. (2016). Lateral flow assays. Essays Biochem. 60, 111-120. doi: 10.1042/EBC20150012

Kong, J., Franklin, N. R., Zhou, C., Chapline, M. G., Peng, S., Cho, K., et al. (2000). Nanotube molecular wires as chemical sensors. Science 287, 622-625. doi: 10.1126/science.287.5453.622

Korff, S., Katus, H. A., and Giannitsis, E. (2006). Differential diagnosis of elevated troponins. Heart 92, 987-993. doi: 10.1136/hrt.2005.071282

Kuriyama, R., Tanaka, Y., Akiyama, S., and Sato, Y. (2011). "Effect of electric double layer on near-wall ph in microfluidic device measured by nano-LIF," in Proceedings of the 15th International Conference on Miniaturized Systems for Chemistry and Life Sciences 2011, MicroTAS 2011, Seattle, WA.

Laflamme, M. A., Sebastian, M. M., and Buetow, B. S. (2012). 10 - Cardiovascular. Comp. Anat. Histol. 135-153. doi: 10.1016/B978-0-12-381361-9.00010-X

Lakshmanakumar, M., Nesakumar, N., Sethuraman, S., Rajan, K. S., Krishnan, U. M., and Rayappan, J. B. B. (2019). Functionalized graphene quantum dot interfaced electrochemical detection of cardiac Troponin I: an antibody free approach. Sci. Rep. 9:17348. doi: 10.1038/s41598-019-53979-5

Li, C., and Wang, L. V. (2009). Photoacoustic tomography and sensing in biomedicine. Phys. Med. Biol. 54, R59-R97. doi: 10.1088/0031-9155/54/19/R01

Li, S., Zhu, J., Zhang, W., Chen, Y., Zhang, K., Popescu, L. M., et al. (2011). Signature microRNA expression profile of essential hypertension and its novel link to human cytomegalovirus infection. Circulation 124, 175-184. doi: 10. 1161/CIRCULATIONAHA.110.012237

Li, Y. Q., Zhang, M. F., Wen, H. Y., Hu, C. L., Liu, R., Wei, H. Y., et al. (2013). Comparing the diagnostic values of circulating microRNAs and cardiac troponin $\mathrm{T}$ in patients with acute myocardial infarction. Clinics $68,75-80$. doi: 10.6061/clinics/2013(01)OA12

Libby, P. (2002). Inflammation in atherosclerosis. Nature 1, 297-329. doi: 10.1038/ nature 01323

Lichtenstein, A. H., and Matthan, N. R. (2007). "Cardiovascular disease," in Optimizing Women's Health through Nutrition, eds L. U. Thompson and W. E. Ward (Boca Raton, FL: CRC Press).

Lim, W. Y., Thevarajah, T. M., Goh, B. T., and Khor, S. M. (2019). Paper microfluidic device for early diagnosis and prognosis of acute myocardial infarction via quantitative multiplex cardiac biomarker detection. Biosens. Bioelectron. 128, 176-185. doi: 10.1016/j.bios.2018.12.049

Liu, G., Qi, M., Zhang, Y., Cao, C., and Goldys, E. M. (2016). Nanocomposites of gold nanoparticles and graphene oxide towards an stable label-free electrochemical immunosensor for detection of cardiac marker troponin-I. Anal. Chim. Acta 909, 1-8. doi: 10.1016/j.aca.2015.12.023

Liu, P., Yang, X., Sun, S., Wang, Q., Wang, K., Huang, J., et al. (2013). Enzyme-free colorimetric detection of DNA by using gold nanoparticles and hybridization chain reaction amplification. Anal. Chem. 85, 7689-7695. doi: 10.1021/ac4001157

Liu, Q., Aroonyadet, N., Song, Y., Wang, X., Cao, X., Liu, Y., et al. (2016). Highly sensitive and quick detection of acute myocardial infarction biomarkers using In2O3 nanoribbon biosensors fabricated using shadow masks. ACS Nano 10, 10117-10125. doi: 10.1021/acsnano.6b05171

Liu, T., Yu, J., Deng, M., Yin, Y., Zhang, H., Luo, K., et al. (2017). CDK4/6dependent activation of DUB3 regulates cancer metastasis through SNAIL1. Nat. Commun. 8:13923. doi: 10.1038/ncomms13923

Liu, Y., Ma, Y., Zhang, J., Yuan, Y., and Wang, J. (2019). Exosomes: a novel therapeutic agent for cartilage and bone tissue regeneration. Dose Response 17:1559325819892702. doi: 10.1177/1559325819892702

Long, G., Wang, F., Duan, Q., Chen, F., Yang, S., Gong, W., et al. (2012a). Human circulating microRNA-1 and microRNA-126 as potential novel indicators for acute myocardial infarction. Int. J. Biol. Sci. 8, 811-818. doi: 10.7150/ijbs.4439

Long, G., Wang, F., Duan, Q., Yang, S., Chen, F., Gong, W., et al. (2012b). Circulating miR-30a, miR-195 and let-7b associated with acute myocardial infarction. PLoS One 7:e50926. doi: 10.1371/journal.pone.00 50926

Lopa, N. S., Rahman, M. M., Ahmed, F., Ryu, T., Sutradhar, S. C., Lei, J., et al. (2019). Simple, low-cost, sensitive and label-free aptasensor for the detection of cardiac troponin I based on a gold nanoparticles modified titanium foil. Biosens. Bioelectron. 136, 381-388. doi: 10.1016/j.bios.2018.11.012 
Lou, D., Fan, L., Ji, Y., Gu, N., and Zhang, Y. (2019a). A signal amplifying fluorescent nanoprobe and lateral flow assay for ultrasensitive detection of cardiac biomarker Troponin I. Anal. Methods 11, 3506-3513. doi: 10.1039/ c9ay01039d

Lou, D., Ji, L., Fan, L., Ji, Y., Gu, N., and Zhang, Y. (2019b). Antibody-oriented strategy and mechanism for the preparation of fluorescent nanoprobes for fast and sensitive immunodetection. Langmuir 35, 4860-4867. doi: 10.1021/acs. langmuir.9b00150

Lu, S., Wang, S., Zhao, J., Sun, J., and Yang, X. (2017). Fluorescence lightup biosensor for MicroRNA based on the distance-dependent photoinduced electron transfer. Anal. Chem. 89, 8429-8436. doi: 10.1021/acs.analchem. $7 \mathrm{~b} 01900$

Lv, H., Zhang, X., Li, Y., Ren, Y., Zhang, C., Wang, P., et al. (2019). An electrochemical sandwich immunosensor for cardiac troponin I by using nitrogen/sulfur co-doped graphene oxide modified with Au@Ag nanocubes as amplifiers. Microchim. Acta 186:416. doi: 10.1007/s00604-019-3526-2

Ma, N., Zhang, T., Yan, T., Kuang, X., Wang, H., Wu, D., et al. (2019). Novel electrochemical immunosensor for sensitive monitoring of cardiac troponin I using antigen-response cargo released from mesoporous Fe3O4. Biosens. Bioelectron. 143:111608. doi: 10.1016/j.bios.2019.111608

Madhurantakam, S., Babu, K. J., Rayappan, J. B. B., and Krishnan, U. M. (2018). Nanotechnology-based electrochemical detection strategies for hypertension markers. Biosens. Bioelectron. 116, 67-80. doi: 10.1016/j.bios.2018. 05.034

Marfella, R., Di Filippo, C., Potenza, N., Sardu, C., Rizzo, M. R., Siniscalchi, M., et al. (2013). CirculatingmicroRNA changes in heart failure patients treated with cardiac resynchronization therapy: responders vs. non-responders. Eur. J. Heart Fail. 15, 1277-1288. doi: 10.1093/eurjhf/hft088

Matsumoto, S., Sakata, Y., Suna, S., Nakatani, D., Usami, M., Hara, M., et al. (2013). Circulating p53-responsive MicroRNAs are predictive indicators of heart failure after acute myocardial infarction. Circ. Res. 113, 322-326. doi: 10.1161/CIRCRESAHA.113.301209

McRobbie, D. W., Moore, E. A., and Graves, M. J. (2017). MRI From Picture to Proton. Cambridge: Cambridge University Press. doi: 10.2214/ajr.182.3. 1820592

Miao, L., Jiao, L., Tang, Q., Li, H., Zhang, L., and Wei, Q. (2019). A nanozymelinked immunosorbent assay for dual-modal colorimetric and ratiometric fluorescent detection of cardiac troponin I. Sens. Actuat. B Chem. 288, 60-64. doi: 10.1016/j.snb.2019.02.111

Mullett, W. M., Lai, E. P. C., and Yeung, J. M. (2000). Surface plasmon resonancebased immunoassays. Methods 22, 77-91. doi: 10.1006/meth.2000.1039

Oerlemans, M. I. F. J., Mosterd, A., Dekker, M. S., de Vrey, E. A., van Mil, A., Pasterkamp, G., et al. (2012). Early assessment of acute coronary syndromes in the emergency department: the potential diagnostic value of circulating microRNAs. EMBO Mol. Med. 4, 1176-1185. doi: 10.1002/emmm.201201749

Osborn, E. A., and Jaffer, F. A. (2013). The advancing clinical impact of molecular imaging in CVD. JACC Cardiovasc. Imaging 6, 1327-1341. doi: 10.1016/j.jcmg. 2013.09.014

Pan, D., Schirra, C. O., Wickline, S. A., and Lanza, G. M. (2014). Multicolor computed tomographic molecular imaging with noncrystalline high-metaldensity nanobeacons. Contrast Media Mol. Imaging 9, 13-25. doi: 10.1002/ cmmi.1571

Phonklam, K., Wannapob, R., Sriwimol, W., Thavarungkul, P., and Phairatana, T. (2020). A novel molecularly imprinted polymer PMB/MWCNTs sensor for highly-sensitive cardiac troponin $\mathrm{T}$ detection. Sens. Actuat. B Chem. 308:127630. doi: 10.1016/j.snb.2019.127630

Pykett, I. L., Buonanno, F. S., Brady, T. J., and Kistler, J. P. (1983). True threedimensional nuclear magnetic resonance neuro-imaging in ischemic stroke: correlation of nmr, x-ray ct and pathology. Stroke 14, 173-177. doi: 10.1161/ 01.STR.14.2.173

Qureshi, A., Gurbuz, Y., and Niazi, J. H. (2012). Biosensors for cardiac biomarkers detection: a review. Sens. Actuat. B Chem. 171-172, 62-76. doi: 10.1016/j.snb. 2012.05.077

Rehman, S. A., Khurshid, Z., Niazi, F. H., Naseem, M., Waddani, H., Al Sahibzada, H. A., et al. (2017). Role of salivary biomarkers in detection of cardiovascular diseases (CVD). Proteomes 5, 4-9. doi: 10.3390/proteomes5030021

Richter, M. M. (2004). Electrochemiluminescence (ECL). Chem. Rev. 104, $3003-$ 3036. doi: $10.1021 / \mathrm{cr} 020373 \mathrm{~d}$
Sandil, D., Sharma, S. C., and Puri, N. K. (2019). Protein-functionalized WO3 nanorods-based impedimetric platform for sensitive and label-free detection of a cardiac biomarker. J. Mater. Res. 34, 1331-1340. doi: 10.1557/jmr. 2018.481

Saraste, A., Nekolla, S. G., and Schwaiger, M. (2009). Cardiovascular molecular imaging: an overview. Cardiovasc. Res. 83, 643-652. doi: 10.1093/cvr/cvp209

Sayed, A. S. M., Xia, K., Salma, U., Yang, T., and Peng, J. (2014). Diagnosis, prognosis and therapeutic role of circulating miRNAs in cardiovascular diseases. Heart Lung Circ. 23, 503-510. doi: 10.1016/j.hlc.2014.01.001

Shan, B., Chai, P., and Zhang, Z. (2013). "Positron emission tomography," in Advanced Topics in Science and Technology in China, eds D. L. Bailey, D. W. Townsend, P. E. Valk, and M. N. Maisey (Berlin: Springer).

Shen, Q., Liu, M., Lü, Y., Zhang, D., Cheng, Z., Liu, Y., et al. (2019). Labelfree electrochemical immunosensor based on a functionalized ionic liquid and helical carbon nanotubes for the determination of cardiac Troponin I. ACS Omega 4, 11888-11892. doi: 10.1021/acsomega.9b01152

Singh, N., Rai, P., Ali, M. A., Kumar, R., Sharma, A., Malhotra, B. D., et al. (2019). A hollow-nanosphere-based microfluidic biosensor for biomonitoring of cardiac troponin i. J. Mater. Chem. B 7, 3826-3839. doi: 10.1039/c9tb00126c

Strianese, M., Staiano, M., Ruggiero, G., Labella, T., Pellecchia, C., and D’Auria, S. (2012). Fluorescence-based biosensors. Methods Mol. Biol. 875, 193-216. doi: 10.1007/978-1-61779-806-1_9

Sun, J., Zhuang, J., Shi, J., Kormakov, S., Liu, Y., Yang, Z., et al. (2019). Highly elastic and ultrathin nanopaper-based nanocomposites with superior electric and thermal characteristics. J. Mater. Sci. 54, 8436-8449. doi: 10.1007/s10853019-03472-1

Sun, Y., Kang, C., Zhang, A., Liu, F., Hu, J., Zhong, X., et al. (2016). Co-delivery of dual-drugs with nanoparticle to overcome multidrug resistance. Eur. J. Biomed. Res. 2, 12-18. doi: 10.18088/ejbmr.2.2.2016

Syedmoradi, L., Ahmadi, A., Norton, M. L., and Omidfar, K. (2019). A review on nanomaterial-based field effect transistor technology for biomarker detection. Microchim. Acta 186:739. doi: 10.1007/s00604-019-3850-6

Tan, G. R., Wang, M., Hsu, C. Y., Chen, N., and Zhang, Y. (2016). Small upconverting fluorescent nanoparticles for biosensing and bioimaging. Adv. Opt. Mater. 4, 984-997. doi: 10.1002/adom.201600141

Tan, X., Zhang, L., Tang, Q., Zheng, G., and Li, H. (2019). Ratiometric fluorescent immunoassay for the cardiac troponin-I using carbon dots and palladiumiridium nanocubes with peroxidase-mimicking activity. Microchim. Acta. 186:280. doi: 10.1007/s00604-019-3375-z

Taruttis, A., Herzog, E., Razansky, D., and Ntziachristos, V. (2010). Real-time imaging of cardiovascular dynamics and circulating gold nanorods with multispectral optoacoustic tomography. Opt. Express. 18, 19592-19602. doi: 10.1364/oe.18.019592

Tijsen, A. J., Creemers, E. E., Moerland, P. D., De Windt, L. J., Van Der Wal, A. C., Kok, W. E., et al. (2010). MiR423-5p as a circulating biomarker for heart failure. Circ. Res. 106, 1035-1039. doi: 10.1161/CIRCRESAHA.110.218297

Tsai, P. C., Liao, Y. C., Wang, Y. S., Lin, H. F., Lin, R. T., and Juo, S. H. H. (2013). Serum microrna-21 and microrna-221 as potential biomarkers for cerebrovascular disease. J. Vasc. Res. 50, 346-354. doi: 10.1159/000351767

Van Schooneveld, M. M., Cormode, D. P., Koole, R., Van Wijngaarden, J. T., Calcagno, C., Skajaa, T., et al. (2010). A fluorescent, paramagnetic and PEGylated gold/silica nanoparticle for MRI, CT and fluorescence imaging. Contrast Media Mol. Imaging 5, 231-236. doi: 10.1002/cmmi.376

Vasantham, S., Alhans, R., Singhal, C., Nagabooshanam, S., Nissar, S., Basu, T., et al. (2020). Paper based point of care immunosensor for the impedimetric detection of cardiac troponin I biomarker. Biomed. Microdevices 22:6. doi: 10.1007/s10544-019-0463-0

Walters, N., Nguyen, L. T. H., Zhang, J., Shankaran, A., and Reátegui, E. (2019). Extracellular vesicles as mediators of in vitro neutrophil swarming on a largescale microparticle array. Lab Chip 19, 2874-2884. doi: 10.1039/c9lc00483a

Wang, G. K., Zhu, J. Q., Zhang, J. T., Li, Q., Li, Y., He, J., et al. (2010). Circulating microRNA: a novel potential biomarker for early diagnosis of acute myocardial infarction in humans. Eur. Heart J. 31, 659-666. doi: 10.1093/eurheartj/ehq013

Wang, S., Zhao, Y., Wang, M., Li, H., Saqib, M., Ge, C., et al. (2019). Enhancing luminol electrochemiluminescence by combined use of cobalt-based metal organic frameworks and silver nanoparticles and its application in ultrasensitive detection of cardiac Troponin I. Anal. Chem. 91, 3048-3054. doi: 10.1021/acs. analchem.8b05443 
Wang, W., Zou, Y., Yan, J., Liu, J., Chen, H., Li, S., et al. (2018). Ultrasensitive colorimetric immunoassay for hCG detection based on dual catalysis of Au@Pt core-shell nanoparticle functionalized by horseradish peroxidase. Spectrochim. Acta Part A Mol. Biomol. Spectrosc. 193, 102-108. doi: 10.1016/j.saa.2017.12. 014

Wang, X., Kwak, K. J., Yang, Z., Zhang, A., Zhang, X., Sullivan, R., et al. (2018). Extracellular mRNA detected by molecular beacons in tethered lipoplex nanoparticles for diagnosis of human hepatocellular carcinoma. PLoS One 13:e0198552. doi: 10.1371/journal.pone.0198552

Wang, X., Yang, Z., Tian, H., Li, Y., Li, M., Zhao, W., et al. (2017a). Circulating MIC-1/GDF15 is a complementary screening biomarker with CEA and correlates with liver metastasis and poor survival in colorectal cancer. Oncotarget 8, 24892-24901. doi: 10.18632/oncotarget.15279

Wang, X., Zhi, X., Yang, Z., Tian, H., Li, Y., Li, M., et al. (2017b). A novel serum based biomarker panel has complementary ability to preclude presence of early lung cancer for low dose CT (LDCT). Oncotarget 8, 45345-45355. doi: 10.18632/oncotarget.17477

Wang, Z., Zong, S., Wu, L., Zhu, D., and Cui, Y. (2017c). SERS-activated platforms for immunoassay: probes, encoding methods, and applications. Chem. Rev. 117, 7910-7963. doi: 10.1021/acs.chemrev.7b00027

Xia, J., Yao, J., and Wang, L. V. (2014). Photoacoustic tomography: principles and advances. Prog. Electromagn. Res. 147, 1-22. doi: 10.2528/PIER14032303

Xue, T. Y., Mei, L. P., Xu, Y. T., Liu, Y. L., Fan, G. C., Li, H. Y., et al. (2019). Nanoporous semiconductor electrode captures the quantum dots: toward ultrasensitive signal-on liposomal photoelectrochemical immunoassay. Anal. Chem. 91, 3795-3799. doi: 10.1021/acs.analchem.9b00170

Yang, Z., Ma, Y., Zhao, H., Yuan, Y., and Kim, B. Y. S. (2020a). Nanotechnology platforms for cancer immunotherapy. Wiley Interdiscip. Rev. Nanomed. Nanobiotechnol. 12, 1-28. doi: 10.1002/wnan.1590

Yang, Z., Shi, J., Xie, J., Wang, Y., Sun, J., Liu, T., et al. (2020b). Largescale generation of functional mRNA-encapsulating exosomes via cellular nanoporation. Nat. Biomed. Eng. 4, 69-83. doi: 10.1038/s41551-019-0485-1

Yang, Z., Sun, W., and $\mathrm{Hu}, \mathrm{K}$. (2009). Adenosine A1 receptors selectively target protein kinase $\mathrm{C}$ isoforms to the caveolin-rich plasma membrane in cardiac myocytes. Biochim. Biophys. Acta Mol. Cell Res. 1793, 1868-1875. doi: 10.1016/ j.bbamcr.2009.10.007

Yang, Z., Sun, W., and Hu, K. (2012). Molecular mechanism underlying adenosine receptor-mediated mitochondrial targeting of protein kinase C. Biochim. Biophys. Acta Mol. Cell Res. 1823, 950-958. doi: 10.1016/j.bbamcr.2011. 12.012

Yang, Z., Xie, J., Zhu, J., Kang, C., Chiang, C., Wang, X., et al. (2016). Functional exosome-mimic for delivery of siRNA to cancer: in vitro and in vivo evaluation. J. Control. Release 243, 160-171. doi: 10.1016/j.jconrel.2016.10.008

Yeh, H. C., Sharma, J., Han, J. J., Martinez, J. S., and Werner, J. H. (2010). A DNA-silver nanocluster probe that fluoresces upon hybridization. Nano Lett. 10, 3106-3110. doi: 10.1021/nl101773c

Yu, H., Yang, Z., Pan, S., Yang, Y., Tian, J., Wang, L., et al. (2015). Hypoxic preconditioning promotes the translocation of protein kinase $\mathrm{C} \varepsilon$ binding with caveolin-3 at cell membrane not mitochondrial in rat heart. Cell Cycle 14, 3557-3565. doi: 10.1080/15384101.2015.1084446

Yu, X., Deng, L., Wang, D., Li, N., Chen, X., Cheng, X., et al. (2012). Mechanism of TNF- $\alpha$ autocrine effects in hypoxic cardiomyocytes: initiated by hypoxia inducible factor $1 \alpha$, presented by exosomes. J. Mol. Cell. Cardiol. 53, 848-857. doi: 10.1016/j.yjmcc.2012.10.002

Zamani, P., Fereydouni, N., Butler, A. E., Navashenaq, J. G., and Sahebkar, A. (2019). The therapeutic and diagnostic role of exosomes in cardiovascular diseases. Trends Cardiovasc. Med. 29, 313-323. doi: 10.1016/j.tcm.2018.10.010

Zeng, L., Liu, J., Wang, Y., Wang, L., Weng, S., Tang, Y., et al. (2011). MicroRNA210 as a novel blood biomarker in acute cerebral ischemia. Front. Biosci. 3:1265-1272. doi: 10.2741/e330

Zhang, J., Nie, H., Wu, Z., Yang, Z., Zhang, L., Xu, X., et al. (2014). Self-catalytic growth of unmodified gold nanoparticles as conductive bridges mediated gapelectrical signal transduction for DNA hybridization detection. Anal. Chem. 86, 1178-1185. doi: 10.1021/ac4032675

Zhang, X., Lv, H., Li, Y., Zhang, C., Wang, P., Liu, Q., et al. (2019). Ultrasensitive sandwich-type immunosensor for cardiac troponin $\mathrm{i}$ based on enhanced electrocatalytic reduction of $\mathrm{H} 2 \mathrm{O} 2$ using $\beta$-cyclodextrins functionalized 3D porous graphene-supported Pd@Au nanocubes. J. Mater. Chem. B 7, 14601468. doi: $10.1039 / \mathrm{c} 8$ tb03362e

Zhao, W. W., Xu, J. J., and Chen, H. Y. (2014). Photoelectrochemical DNA biosensors. Chem. Rev. 114, 7421-7441. doi: 10.1021/cr500100j

Zhao, W. W., Yu, P. P., Shan, Y., Wang, J., Xu, J. J., and Chen, H. Y. (2012). Exciton-plasmon interactions between CdS quantum dots and Ag nanoparticles in photoelectrochemical system and its biosensing application. Anal. Chem. 84, 5892-5897. doi: 10.1021/ac300127s

Zhou, C., Yang, Z., and Teng, L. (2014). Nanomedicine based on nucleic acids: pharmacokinetic and pharmacodynamic perspectives. Curr. Pharm. Biotechnol. 15, 829-838. doi: 10.2174/1389201015666141020155620

Zhu, D., Liu, W., Zhao, D., Hao, Q., Li, J., Huang, J., et al. (2017). Label-free electrochemical sensing platform for MicroRNA-21 detection using thionine and gold nanoparticles co-functionalized MoS2 nanosheet. ACS Appl. Mater. Interfaces 9, 35597-35603. doi: 10.1021/acsami.7b11385

Zhu, L., Ye, J., Yan, M., Zhu, Q., Wang, S., Huang, J., et al. (2019). Electrochemiluminescence immunosensor based on $\mathrm{Au}$ nanocluster and hybridization chain reaction signal amplification for ultrasensitive detection of cardiac Troponin I. ACS Sens. 4, 2778-2785. doi: 10.1021/acssensors.9b01369

Zou, B., Cheng, H., and Tu, Y. (2019). An electrochemiluminescence immunosensor for myoglobin using an indium tin oxide glass electrode modified with gold nanoparticles and platinum nanowires. Microchim. Acta 186:598. doi: 10.1007/s00604-019-3703-3

Conflict of Interest: The authors declare that the research was conducted in the absence of any commercial or financial relationships that could be construed as a potential conflict of interest.

The reviewer MK declared a shared affiliation, with no collaboration, with one of the authors, YM, to the handling Editor at the time of review.

Copyright () 2020 Shi, Xie, Ma, Yang and Zhang. This is an open-access article distributed under the terms of the Creative Commons Attribution License (CC BY). The use, distribution or reproduction in other forums is permitted, provided the original author(s) and the copyright owner(s) are credited and that the original publication in this journal is cited, in accordance with accepted academic practice. No use, distribution or reproduction is permitted which does not comply with these terms. 